\title{
الإقتصاديات الأوروبية في مواجهة الأزمة المالية و أزمة الايون السيادية
}

\author{
د. بوعروج لمياء \\ كلية العلوم الاقتصادية \\ جامعة عبد الحميد مهري \\ قسنطينة2(الجز ائر)
}

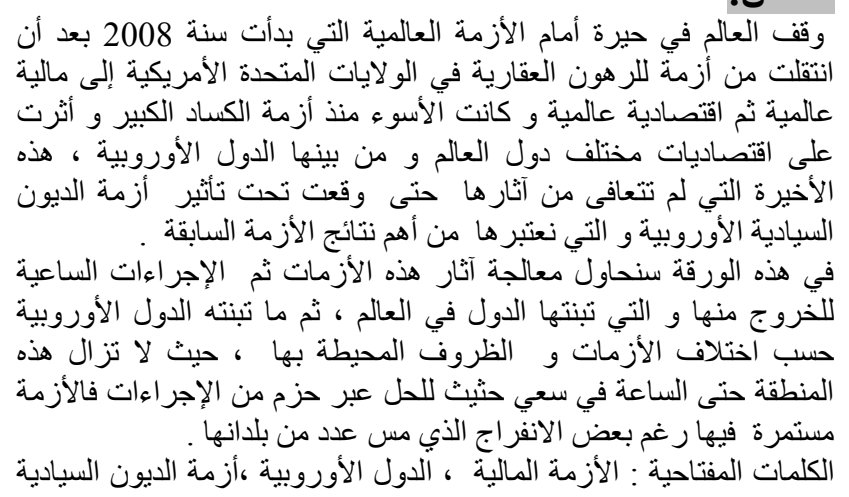

\section{Résumé:}

تعرض العالم في السنوات

La crise économique mondiale des années 2008 et suivantes est considérée comme la pire depuis la Grande Dépression ,c'est une crise de récession dans laquelle sont entrés

la plupart des pays industrialisés du monde suite a la transformation de la crise des sub -primes

aux États-Unis en crise financière mondiale puis en crise économique mondiale.

les États-Unis ont été les premiers à entrer en crise suivi par plusieurs pays occidentaux ainsi que la zone euro dans son ensemble, depuis plusieurs pays ont renoué avec la croissance, par contre plusieurs pays européens n'ont pas pu sortir de ce désastre a cause de l'explosion d'une autre crise depuis 2010 , celle de la dette souveraine qui a touché plusieurs pays notamment les PIIGS.

Dans cet article, nous allons essayer d'aborder les effets de ces crises, et discuter les solutions adoptées par les pays européens en fonction des circonstances et leurs résultats.

Mots clé : la crise financière, pays européens, la crise de la dette souveraine. 


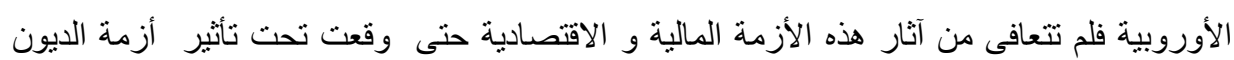

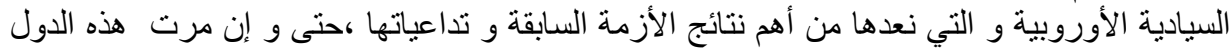

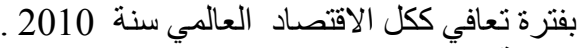

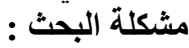

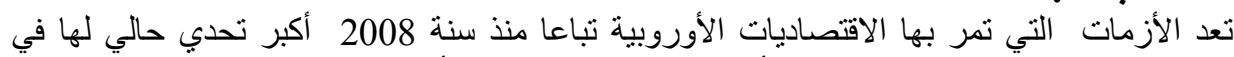

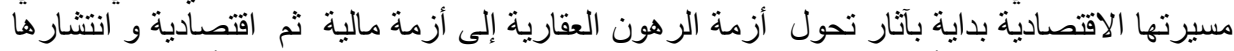

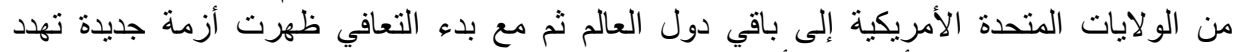

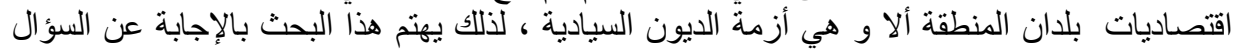

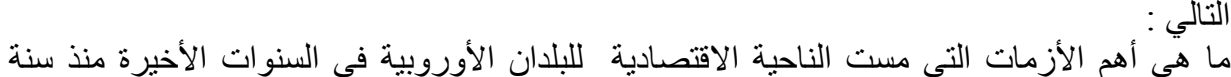

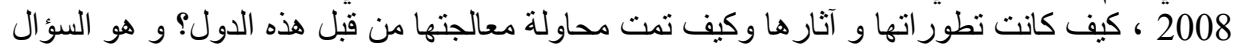

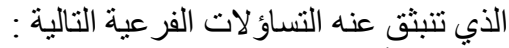

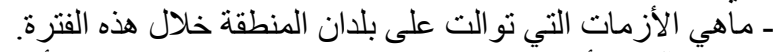

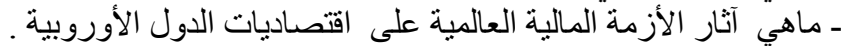

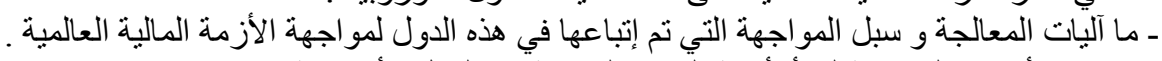

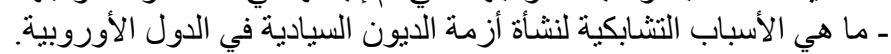

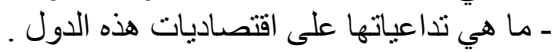

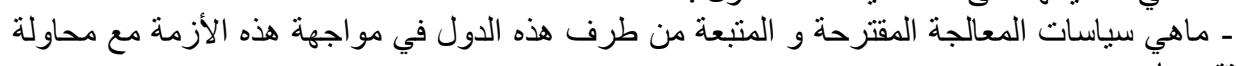

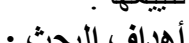

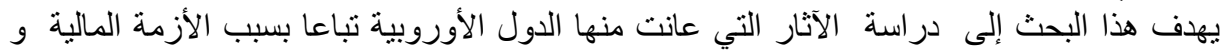

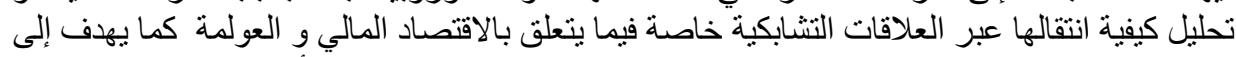

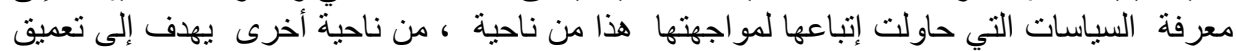

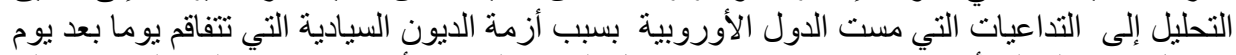

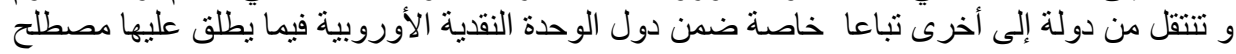

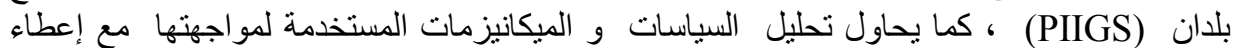
تقييم لهذه السياسات العلاجية.

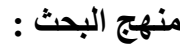

لقد تم توظيف المنهج الوصفي التحليلي في خدمة هذا البحث من أجل تصوئ تصوير الوضع و وتحديد

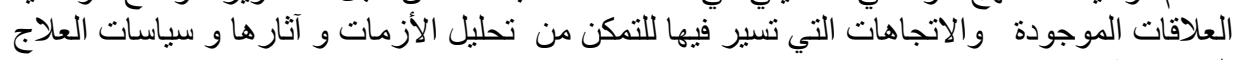
المستخدمة . المبات

$$
\begin{aligned}
& \text { عناصر البحث : }
\end{aligned}
$$

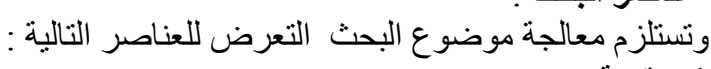

2- الدول الأوروبية في مواجهة الأزمة العالمية خلال سنوات 2008- 2009 و نتناول فيه الأزمة

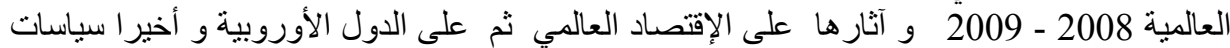

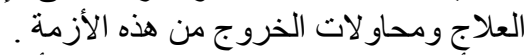

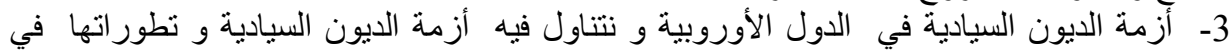

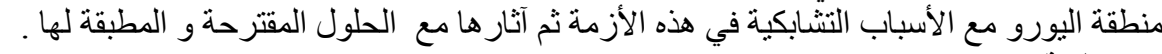




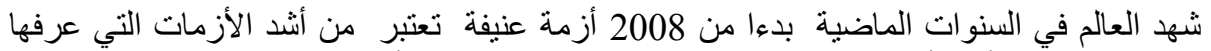

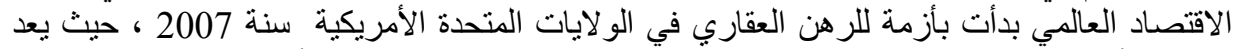

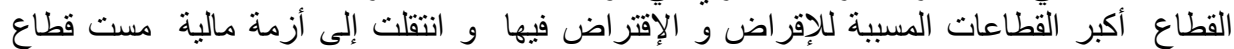

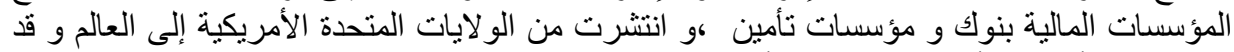

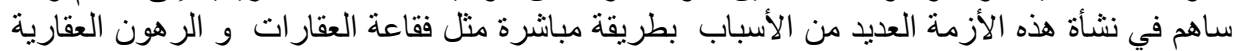

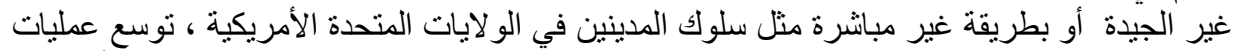

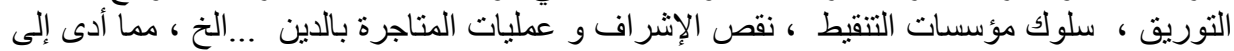

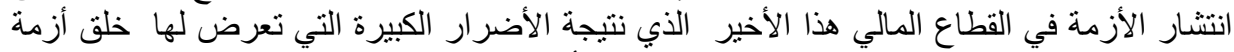

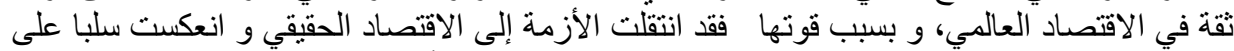

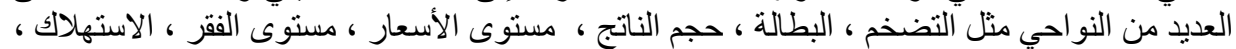

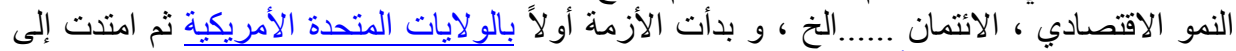

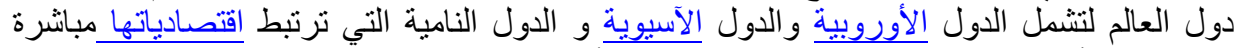
بالاقتصاد الأمريكي ، ثم باقي الدول بآثار مباشرة أو غبرة مبانشرة و و عموما يمكن تقديم هذه الآثار

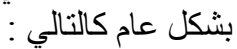

2- اثار الأزمة على الإقتصاد العالمي ثم على الدول الأوروبية :

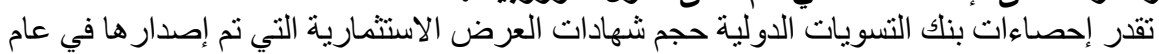

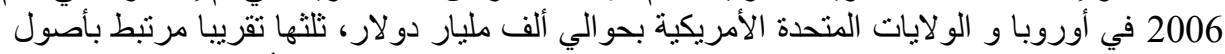

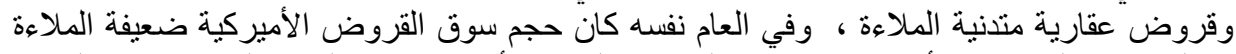

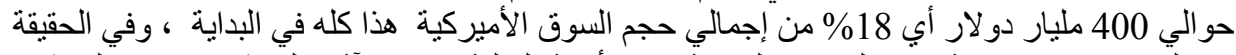

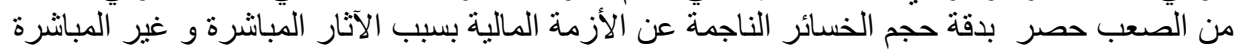

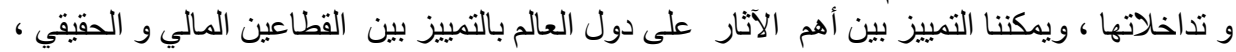

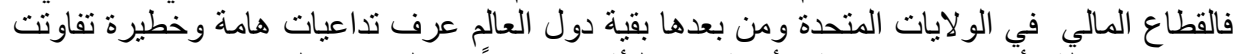

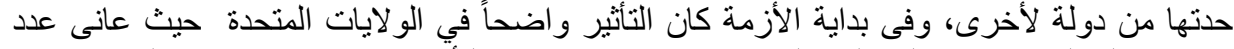

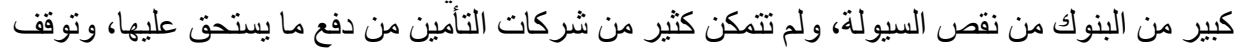

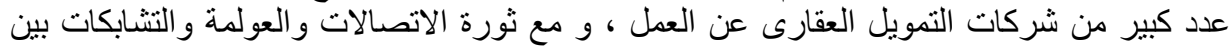

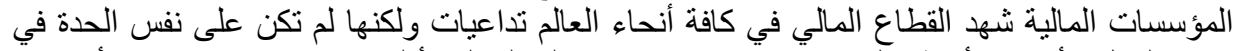

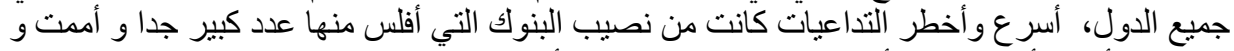

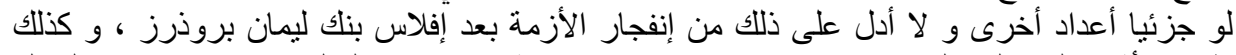

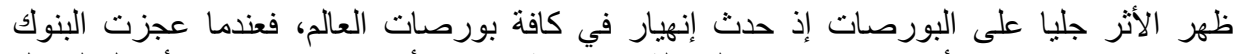

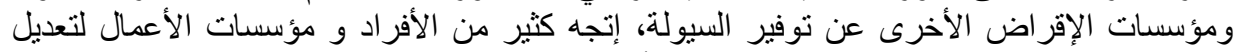

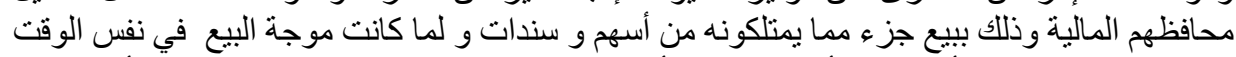

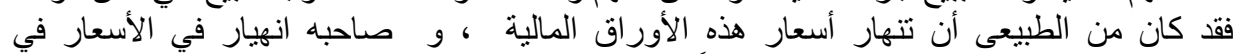

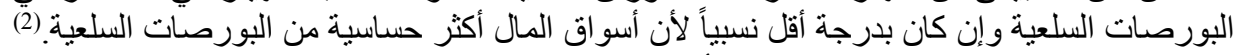

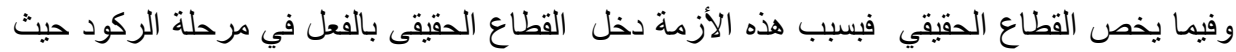

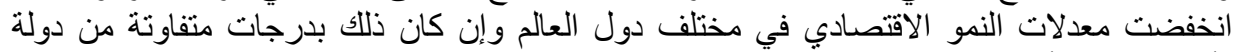

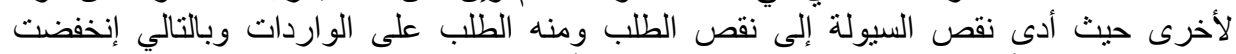

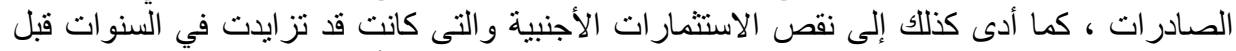

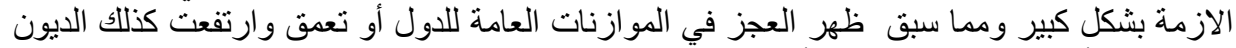

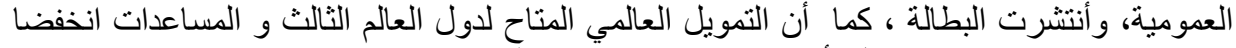

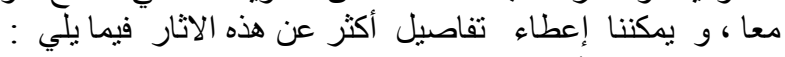

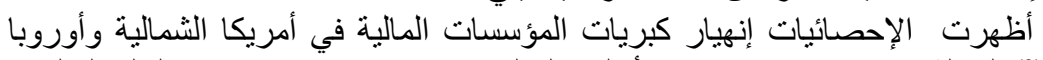

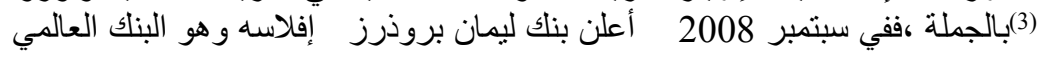


ذي المرتبة الرابعة بين أكبر بنوك الاستثمار ، وهذه كانت بداية رمزية خطرة، لأن هذه فئه

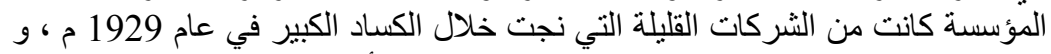

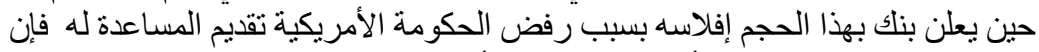

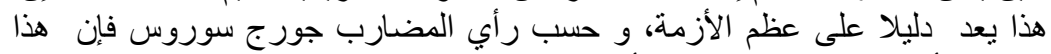

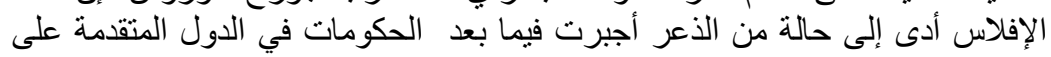

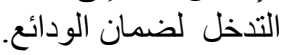

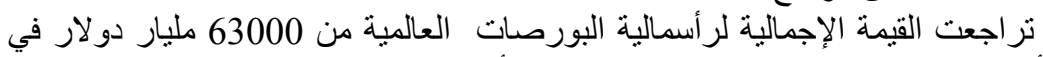
أكتوبر 2007 م إلى الى 49000 مليار مع نهاية أوت 2008 م التتخفض إلى 2008 من 21000 مليار في

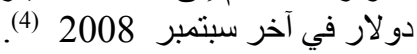

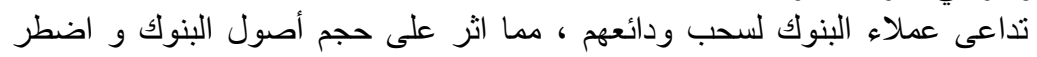

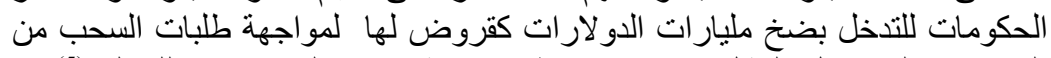

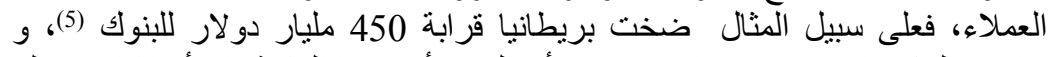

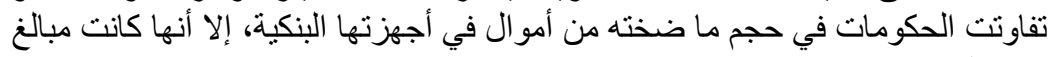

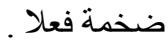

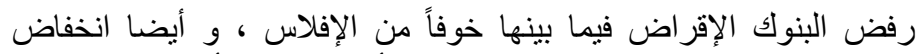

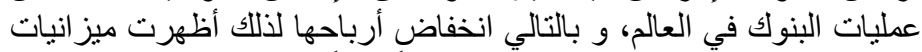

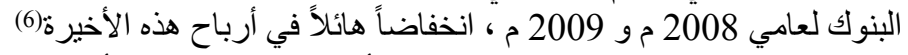

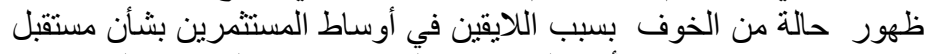

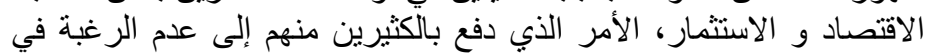

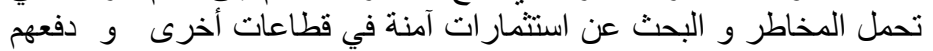

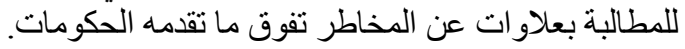

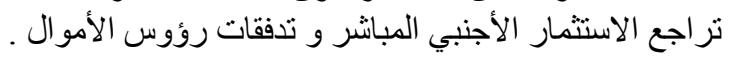

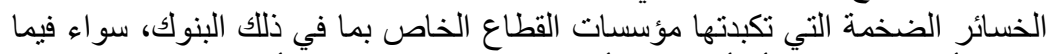

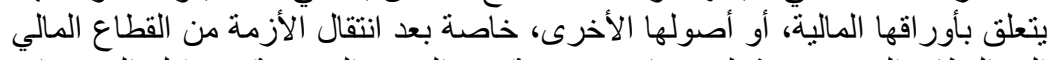

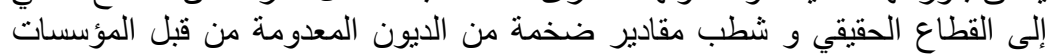
المالية الأخرى . الكئ.

وقد أُدت الأزمة إلى ت تخفيض السيولة في العالم مما أدى إلى انخفاض أحجام الآتمان

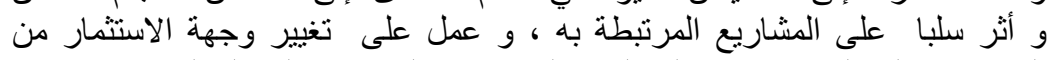

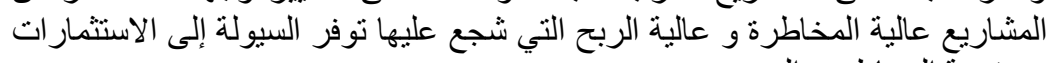

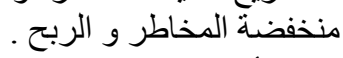

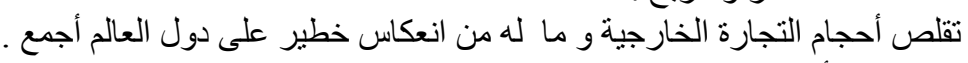

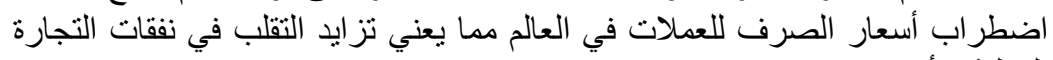

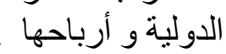

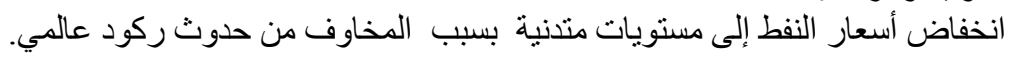

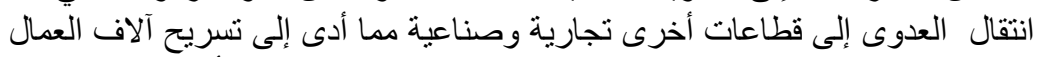

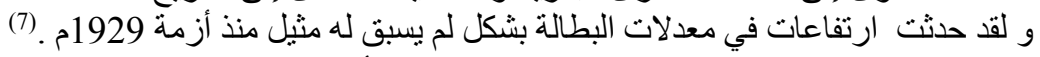

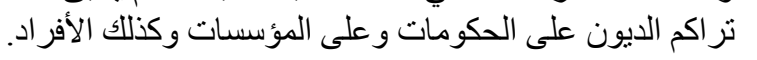

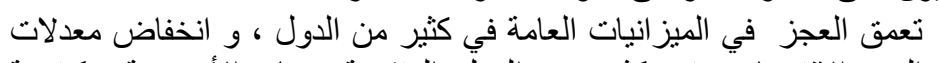

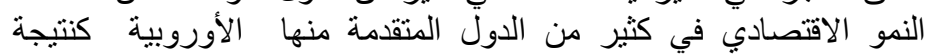
لانخفاض النشاطٌ الاقتصادي في ، و لقد كلفت الأزمة المالية ما بين 3 و 7 نقاط كلاط 
من النمو للاول المنقدمة سنة 2009(8) ،و وفيما يلي شكل يوضح نأثر النمو في

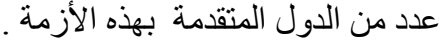

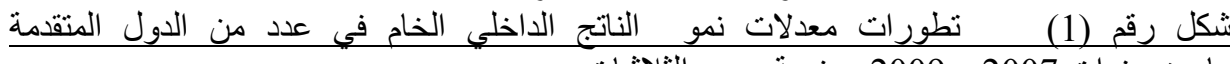
ما بين سنو ات 2007 و 2009 موز عة حسب الثناثيات

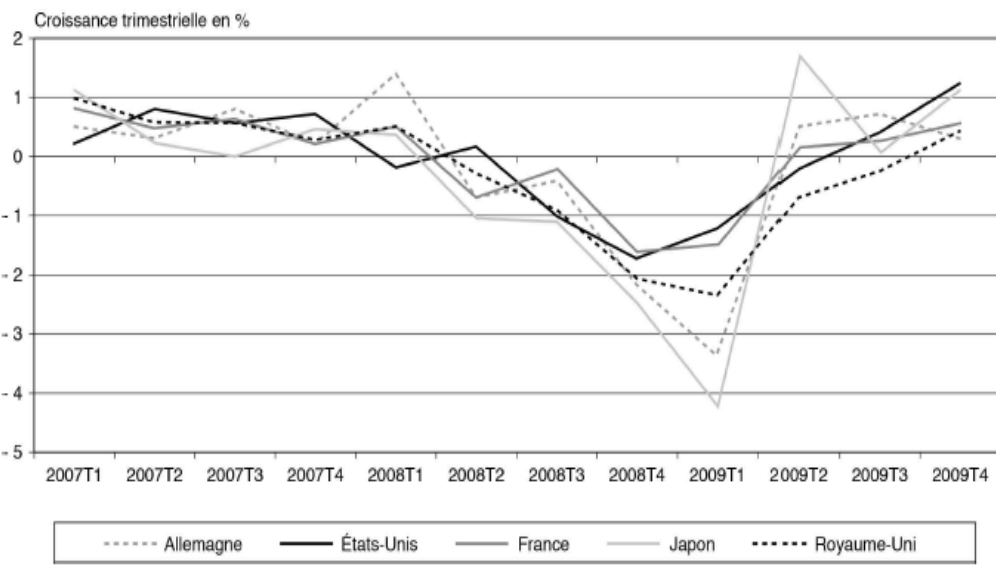

Source : Comptes nationaux trimestriels, instituts de statistiques nationaux des pays représentés.

يمكننا الشكل بوضوح من ملاحظة التذبذب و الاتجاه العام نحو الانخفاض في مستويات نمو الناتج الأخلي الخام في عدد من الدول المتقدمة في العالم حتى أصبحت نسب النساه النمو سلبية خلال فترة هذه

بالنسبة لأوروبا فمن المعروف أن السوق الأمريكية نرتبط ارتباطا عضويا بالاقتصاد الأزمة.

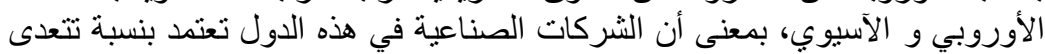

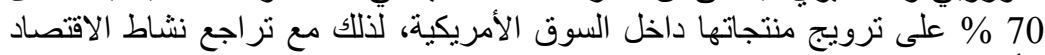

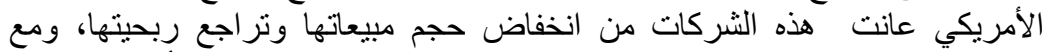

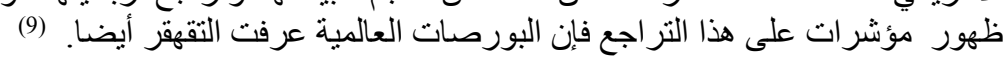

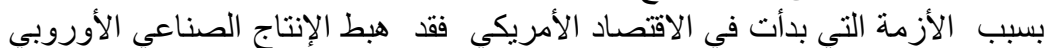

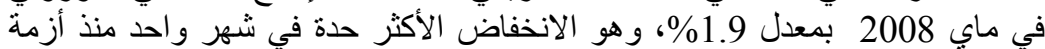
سعر الصرف 1992 ، و سجل الاقتصاد الأوروبي في الربع الثاني من العام انخفاضاً قدره 0.2 \% \%

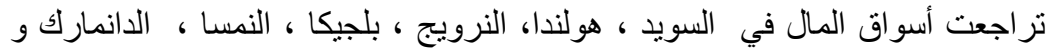
فنلندا ، و انخفض مؤشر البورصة في كل من بريطانيا و ألمانيا وفرنسا و إيطاليا و اليابان كل المظاهر السابقة الخاصة بالأزمة انتقلت بدور ها إلى الدول الأخرى ضمن الدوب

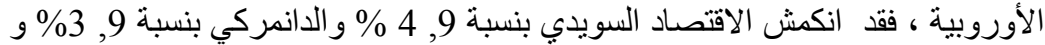

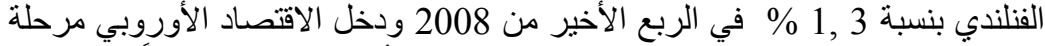

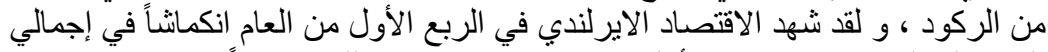

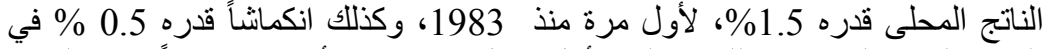

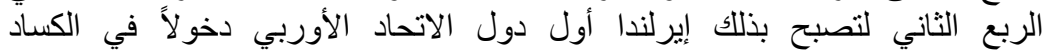

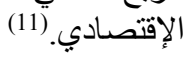


نجت إسبانيا من الانكماش في النشاط الاقتصادي إلا أنها عانت من ارتفاع شديد في والبي

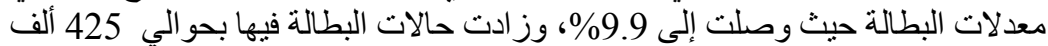

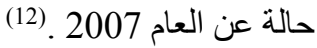

ارتفعت البطالة في الاقتصاد البريطاني إلى وذللك في أوت 2008 ، حسب تقرير عن نأثير الركود الاقتصادي على سوق العمل في اليط

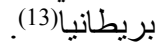

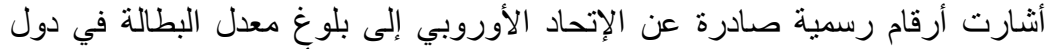

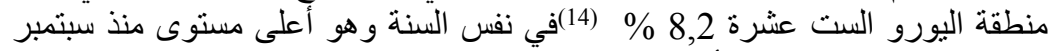

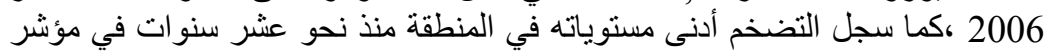

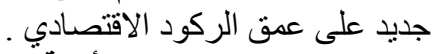

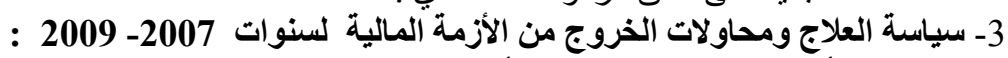

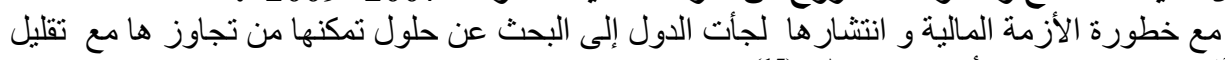

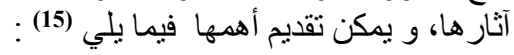

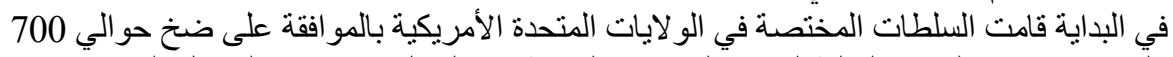

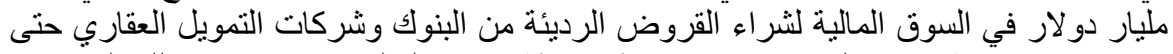

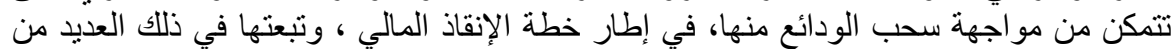

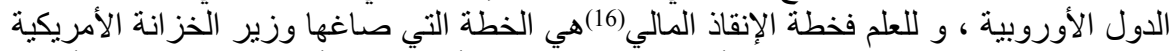

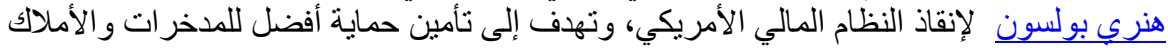

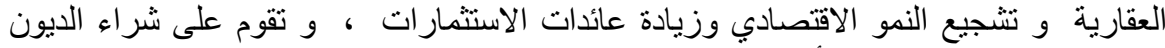

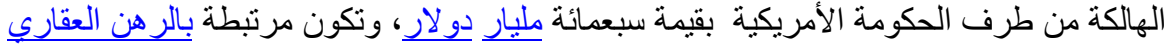

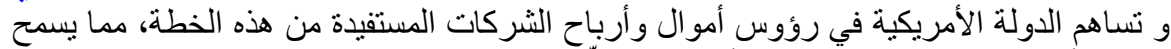

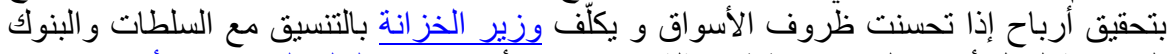

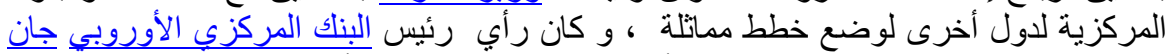

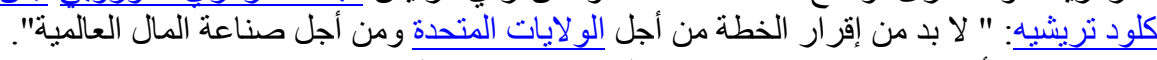

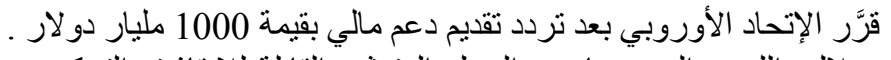

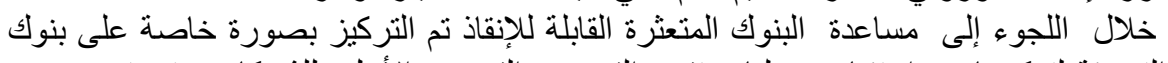

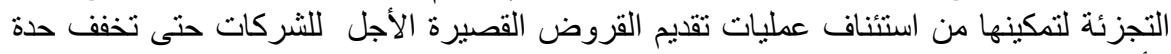

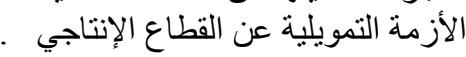

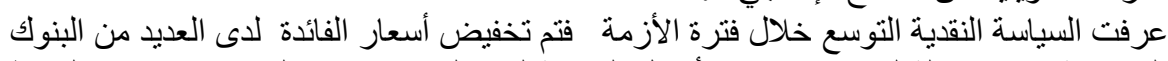

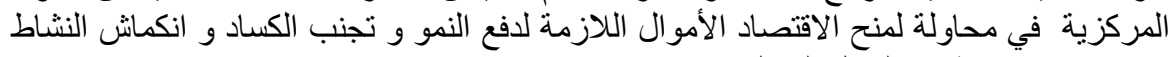

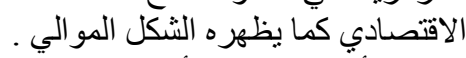

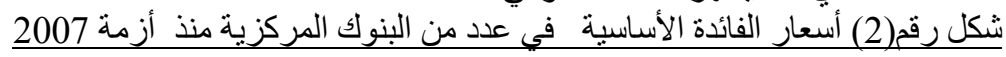




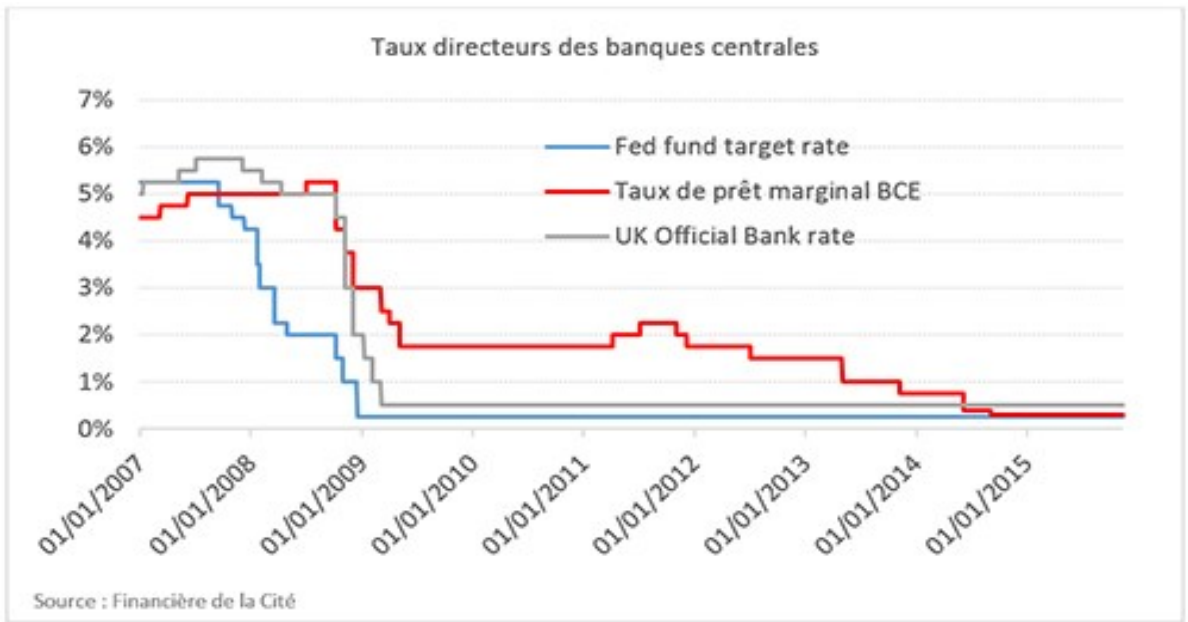

Source : financiére de la cité, retrieved from https://www.financieredelacite.com

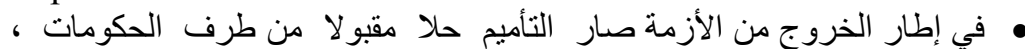

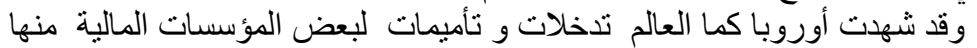

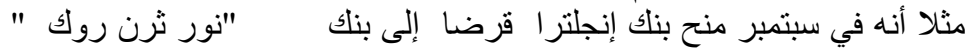

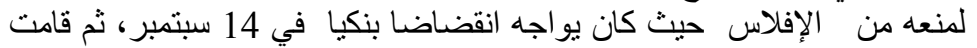

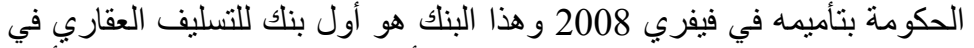

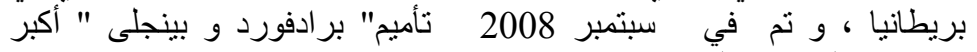

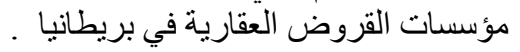

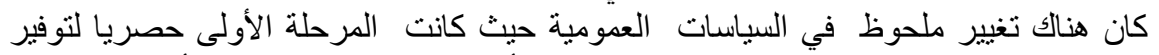

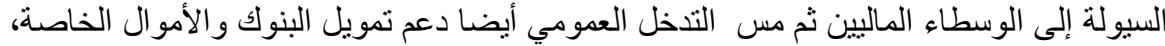

و هذا تغيير هام. (17)

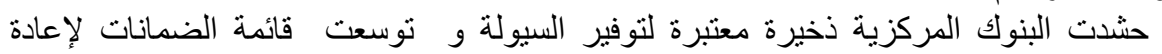

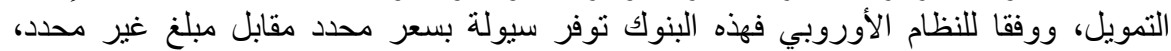

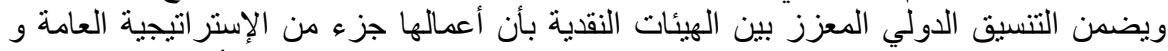

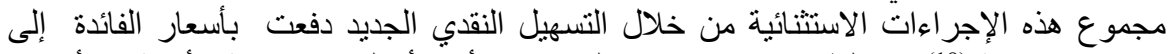

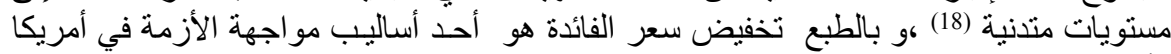

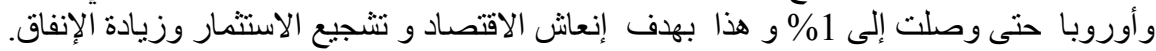

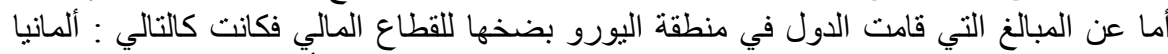

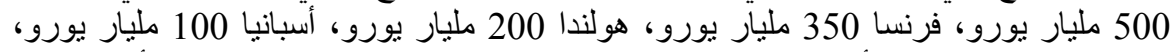

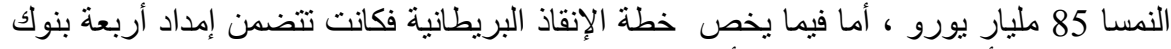

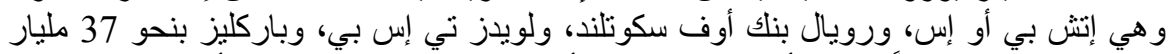

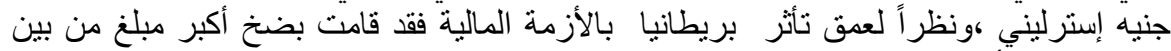

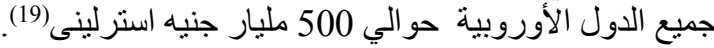

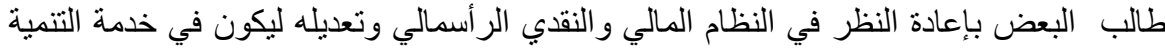

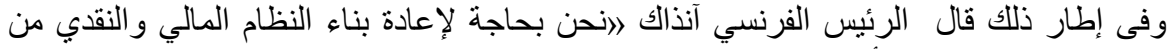
جذوره وإن فكرة وجود أسو اق بصلاحيات مطلقة بذون قيود وبذون لإن تدخل من الحكومات هي فكرة

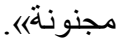


و في الواقع تمكن الاقتصاد العالمي من تجاوز هذه الفترة الحرجة ، و و بدأت بو ادر الخروج من الأزمة

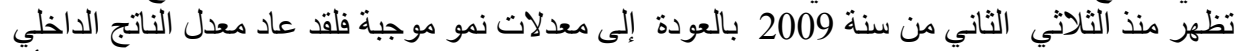

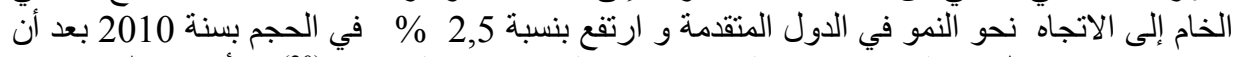

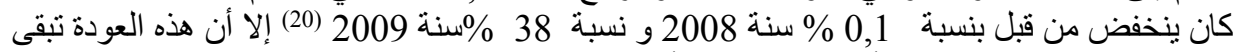

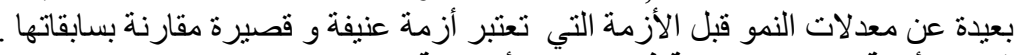

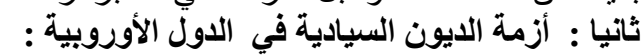

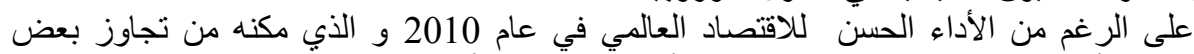

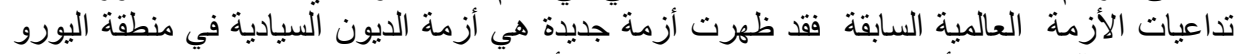

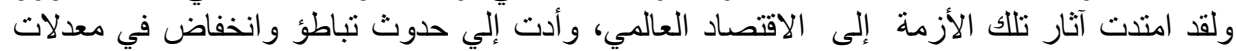

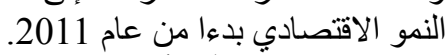

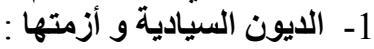

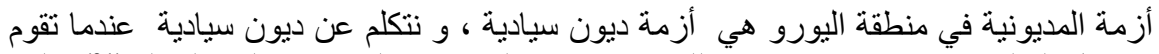

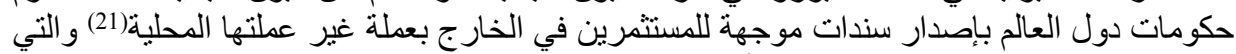

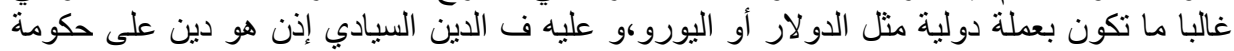

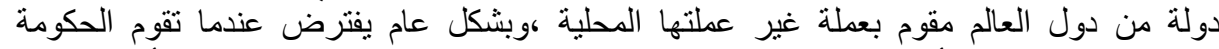

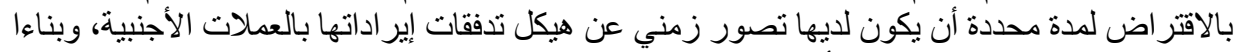

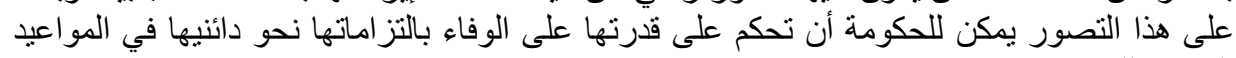

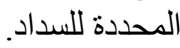

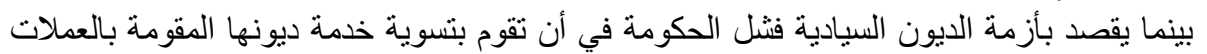

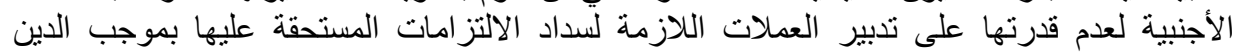

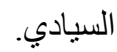

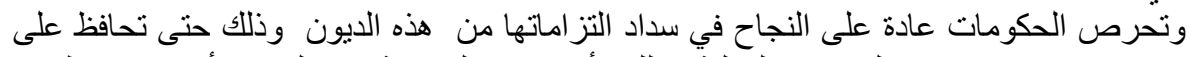

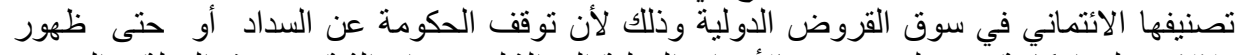

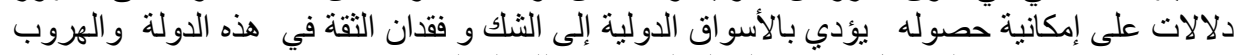

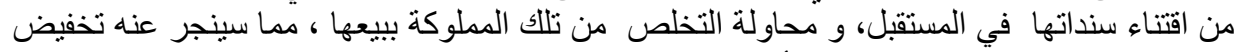

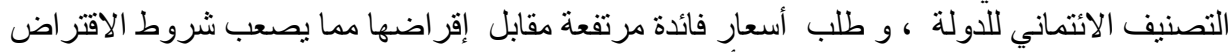

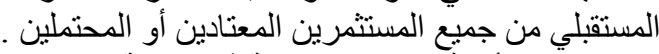

2-نطورات أزمة الديون السيادية في منطقة اليورو انتشارها:

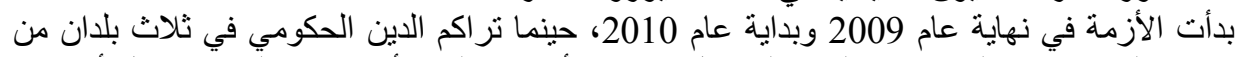

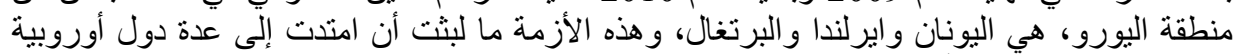

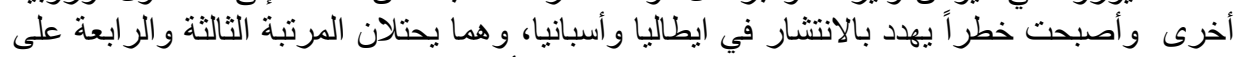

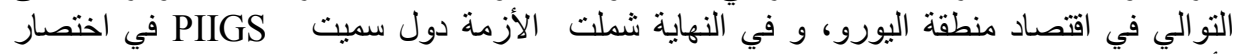
لأسماء مجموعة من الدول هي البرتغال ، ايرلندا ، ايطاليا ، اليونان و اسبانيا ، و و قد انضمت لهات لهات

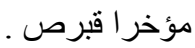

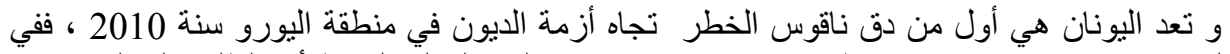

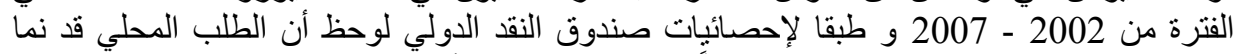

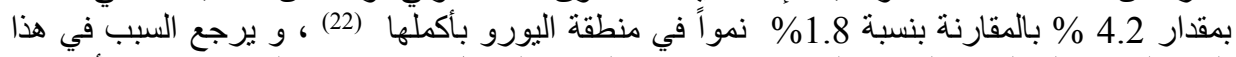

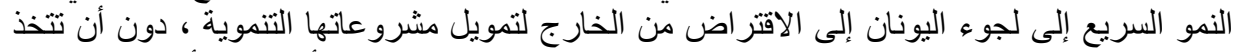

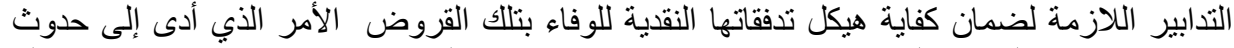

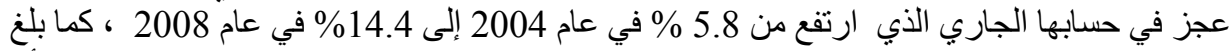

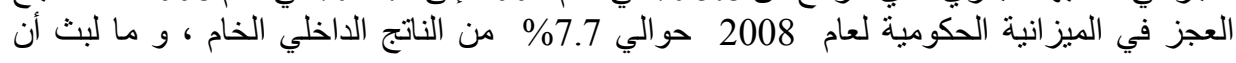




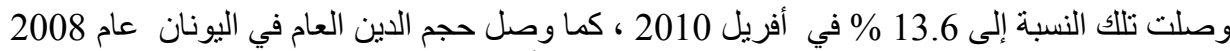

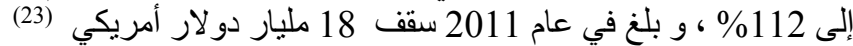

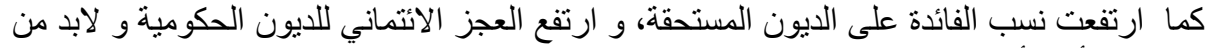

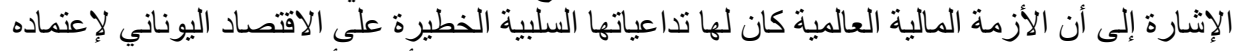

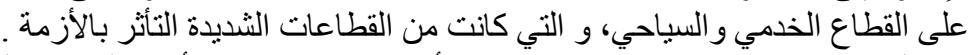

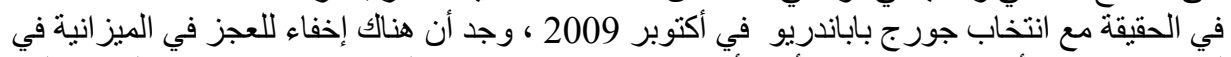

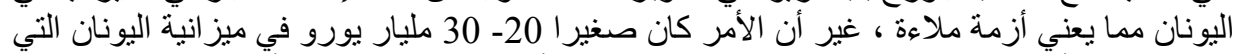

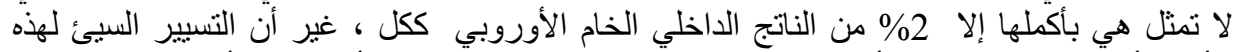

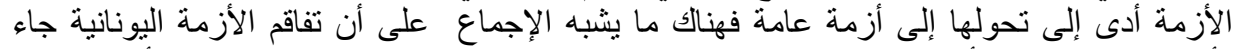

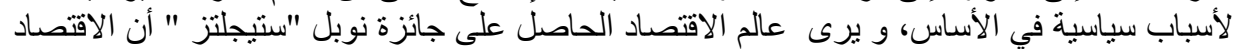

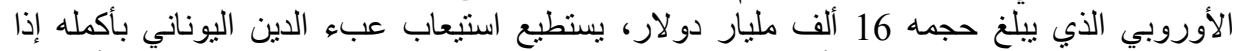

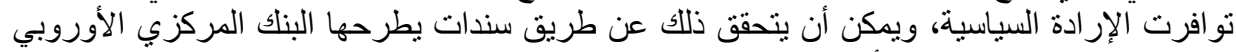

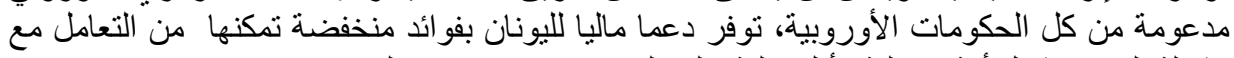

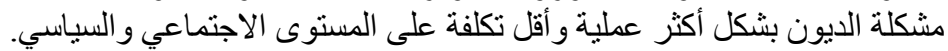

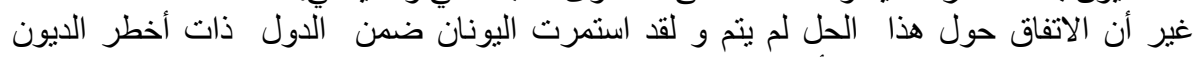

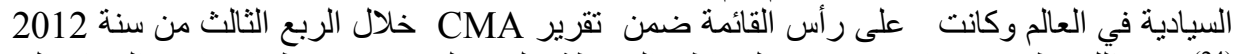

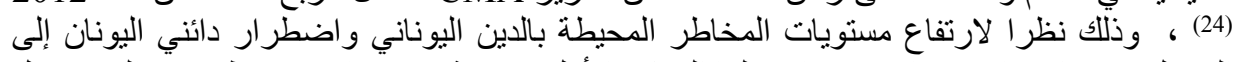

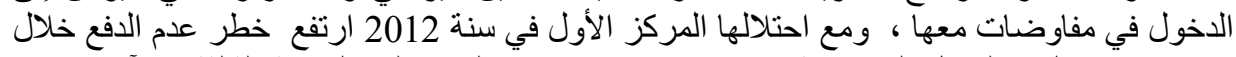

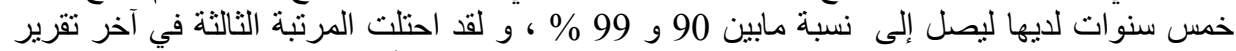

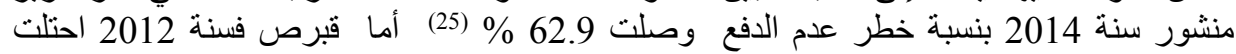
المرتبة الثانية مع نسبة خطر عدم الافع وصلت 57.3 \% و و في سنة 2014 و 2014 انخفضت هذه النسبة إلى النى

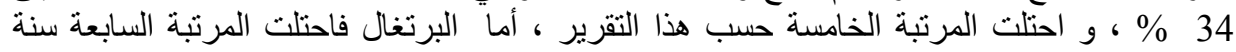

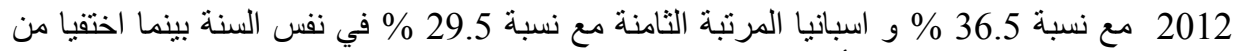

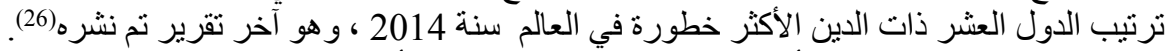

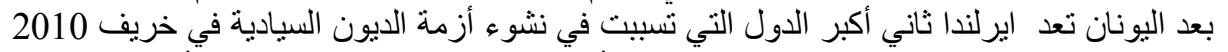

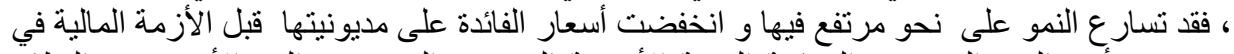

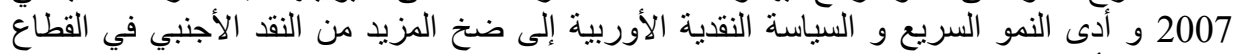

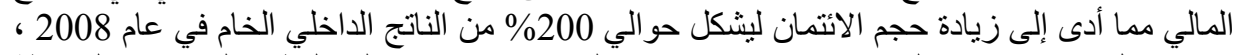

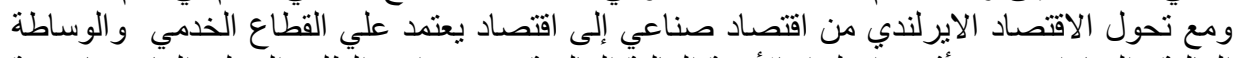

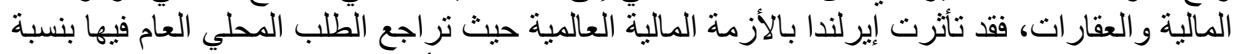

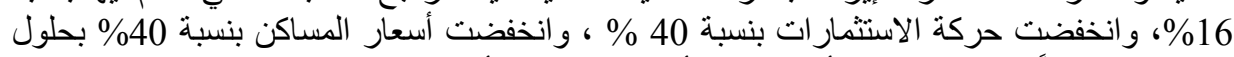

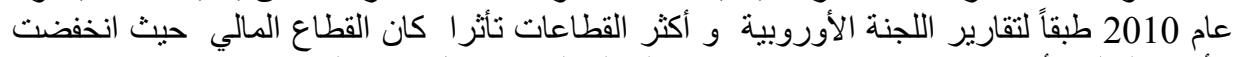

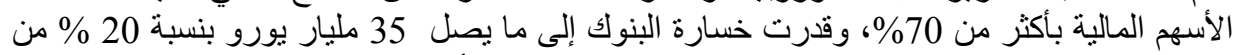

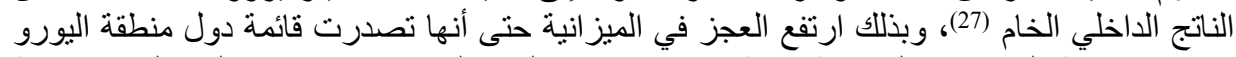

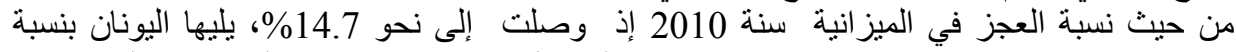

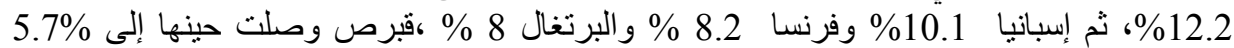

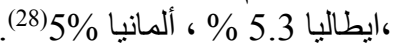

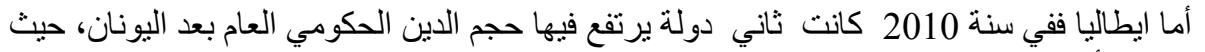

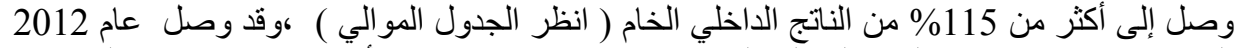

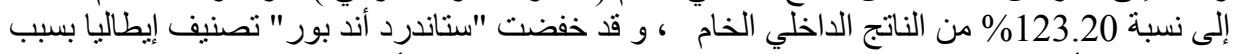
نظرتها إلى أن ايطاليا غير قادرة على خفض الإلى الإنفاق العام وضبط أوضاعها المالية، خاصة في ظل 


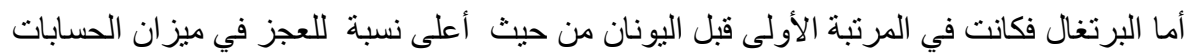

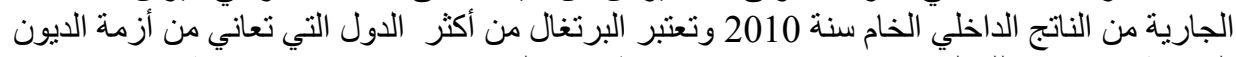

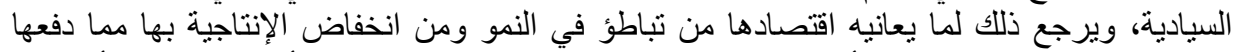

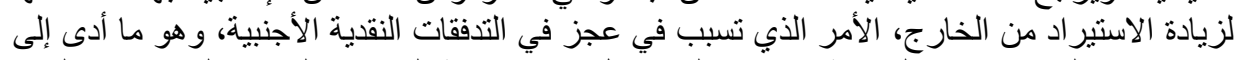

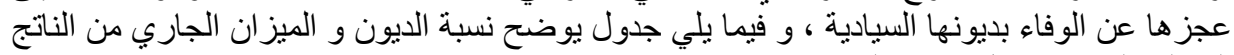

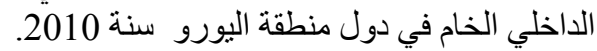

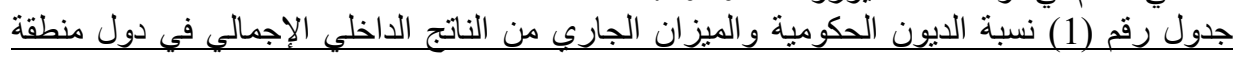

\begin{tabular}{|c|c|c|c|c|c|}
\hline \multicolumn{6}{|c|}{ اليورو عام 2010 ، الوحدة النسبة المؤوية من الناتج الداخلي الخام } \\
\hline المبزانة رصيا & الإجكومية $\quad$ الدين & 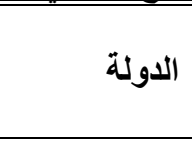 & التبزية ريان & الإجمبة & 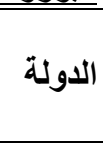 \\
\hline 0.57 & 87.40 & إيرلندا & 3.36 & 82.40 & النمسا \\
\hline-3.47 & 115.29 & إيطاليا & 1.76 & 99.56 & بلجيكا \\
\hline 2.31 & 39.79 & لاتيفيا & -8.97 & 56.49 & 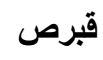 \\
\hline 6.96 & 19.63 & 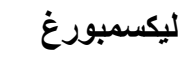 & 1.79 & 6.53 & استونيا \\
\hline-5.92 & 67.61 & مالطا & 2.39 & 46.57 & فنلندا \\
\hline 6.89 & 59.00 & هولاندا & -0.83 & 81.45 & فرنسا \\
\hline-10.15 & 96.18 & البرتغال & 5.69 & 80.25 & ألماتيا \\
\hline-4.73 & 41.10 & تيا تثيكوسلوفاك & -10.10 & 145.66 & اليونان \\
\hline-3.92 & 60.06 & اسبانيا & -0.079 & 37.92 & 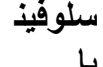 \\
\hline
\end{tabular}

Source: International Monetary Fund, World Economic Outlook Database, April 2015 retrieved le 24-02-2016

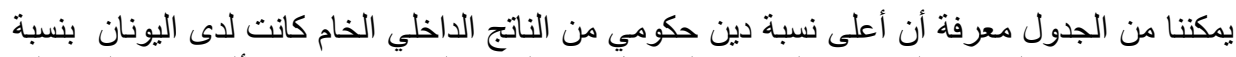

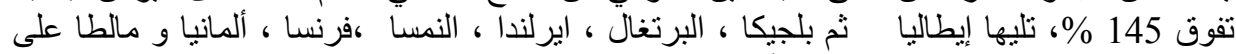

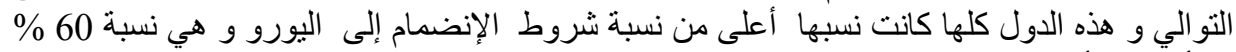

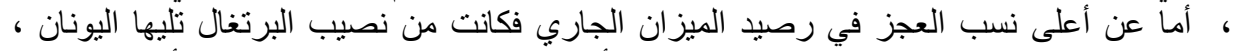

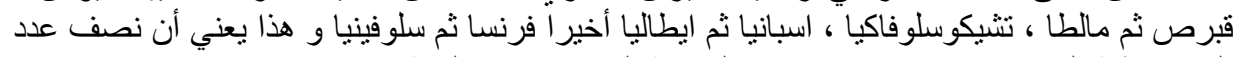

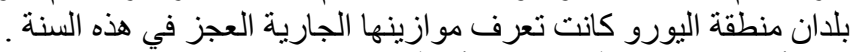

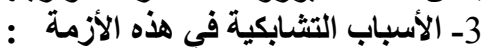
إن الأسباب التي أدت إلى اندلاع هذه الأزمة الأبة متشابكة و ليست فقط العجز في الميزانيات أو في الموازين

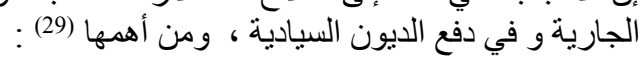


تفجر فقاعة أسعار الأصول في عدد من الدول التابعة لمنطقة اليورو بسبب الارتفاع الثديد

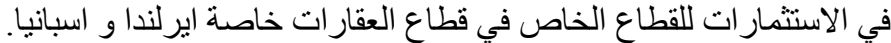

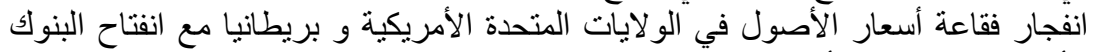

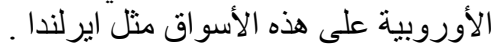
• غياب تقدير البنوك للمخاطر الثديدة التي يتحملونها في عملياتهم الإقراضية.

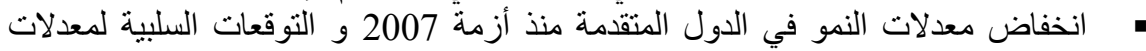

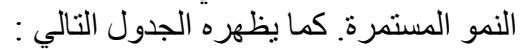

\begin{tabular}{|c|c|c|c|c|c|c|c|c|c|c|}
\hline 2015 & 2014 & 2013 & 2012 & 2011 & 2010 & 2009 & 2008 & 2007 & 2006 & الدولة / السنة \\
\hline 2.718 & 2.553 & 1.665 & 0.659 & 1.645 & 1.911 & 4.311- & $0.332-$ & 2.556 & 3.04 & بريطانيا \\
\hline 2.44 & 1.38 & $1.22-$ & 2.09- & $0.62-$ & 0.01 & $3.57-$ & 1.11 & 3.76 & 4.17 & اسباتيا \\
\hline 1.60 & 0.90 & $1.60-$ & 4.02- & $1.82-$ & 1.89 & 2.97- & 0.11 & 2.49 & 1.55 & البرتغال \\
\hline 0.15 & $2.25-$ & $5.35-$ & $2.38-$ & 0.26 & 1.39 & 2.04- & 3.62 & 4.89 & 4.51 & قبرص \\
\hline 2.52 & 0.77 & 3.89- & $6.57-$ & 8.86- & 5.44- & 4.39- & $0.44-$ & 3.53 & 5.81 & اليونان \\
\hline 3.86 & 4.78 & 0.17 & $0.31-$ & 2.77 & $0.27-$ & $6.37-$ & 2.61- & 4.93 & 5.47 & ايرلندا \\
\hline 0.48 & $0.41-$ & 1.69- & $2.77-$ & 0.58 & 1.71 & $5.48-$ & $1.05-$ & 1.47 & 2 & ايطاليا \\
\hline 3.13 & 2.38 & 2.21 & 2.32 & 1.60 & 2.53 & $2.77-$ & $0.29-$ & 1.77 & 2.66 & الأمريكية الولاية المتحدة \\
\hline
\end{tabular}

Source: International Monetary Fund, World Economic Outlook Database, April 2015 retrieved le 24-02-2016

يمكننا الجدول السابق و بشكل واضح من التعرف على مدى الأثر السلبي الذي كان للأزمة المالية

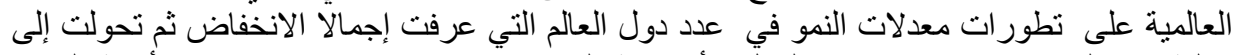

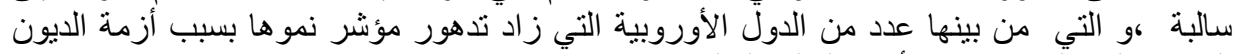
السيادية التي تلت مبانشرة الأزمة المالية العالمية.

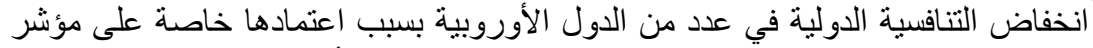

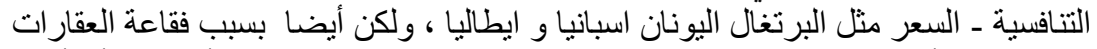

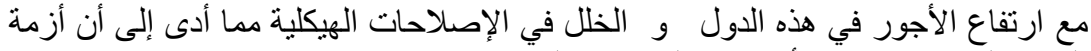

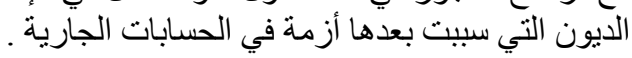

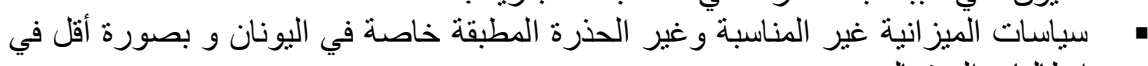




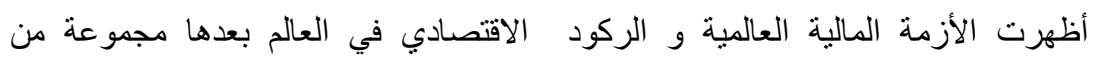

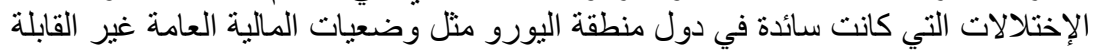

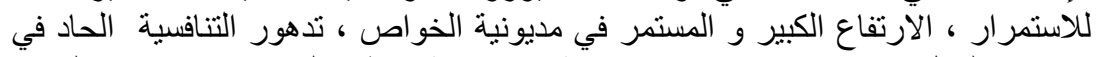

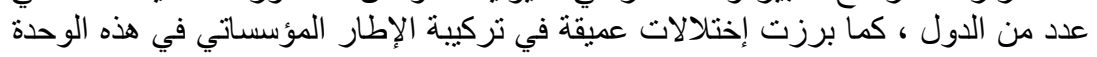

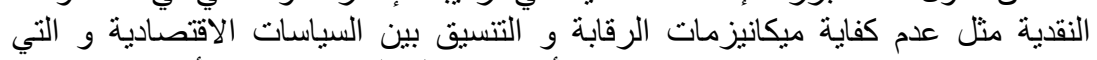

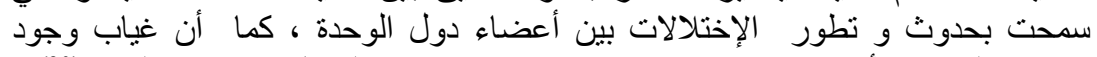

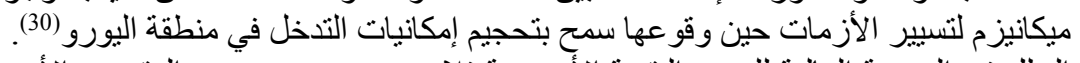

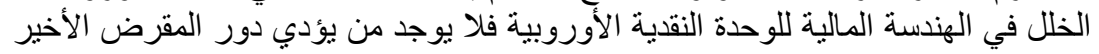

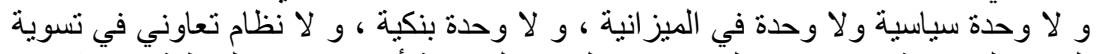

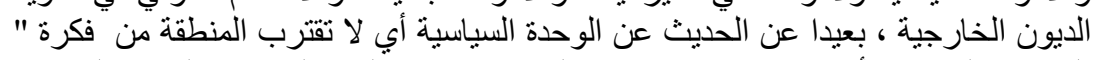

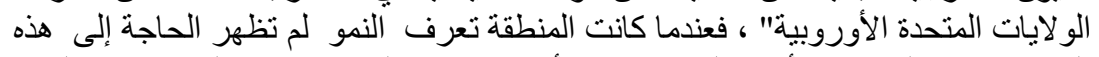

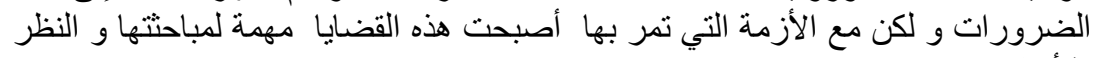
برنانها.

طريقة تسيير أزمة الديون السيادية داخل منطقة اليورو منذ 2013 فمثنا منذ البداية و حتى لإنى

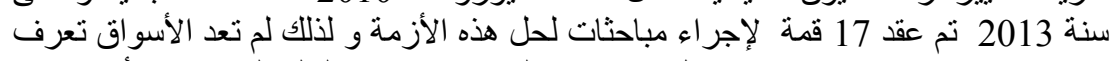

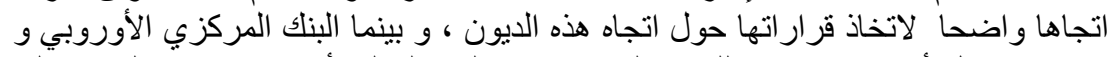

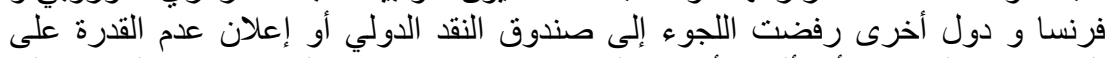

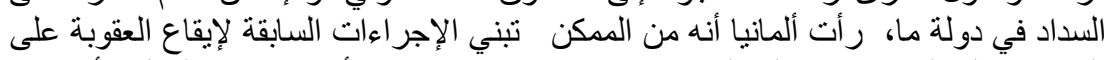

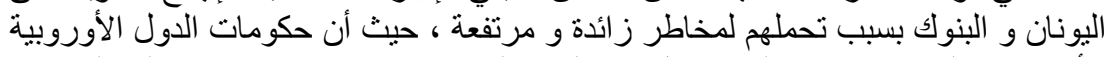

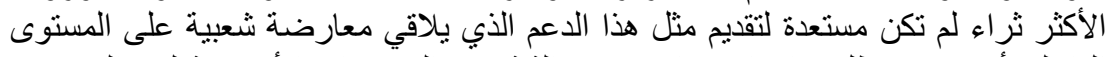

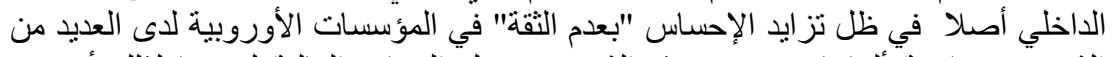

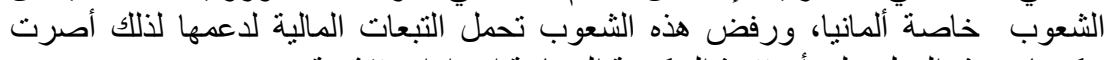

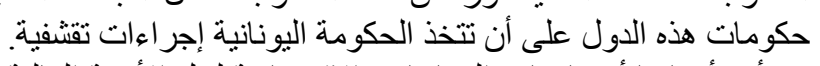

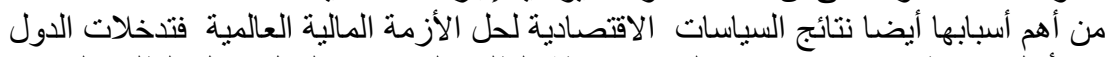

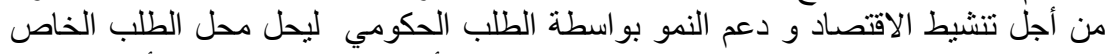

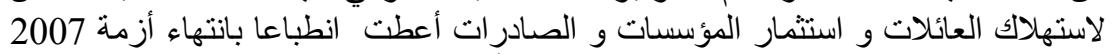

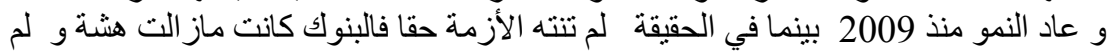

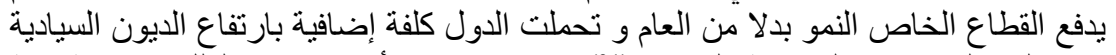

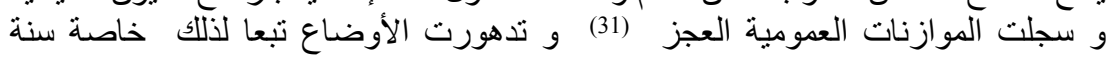

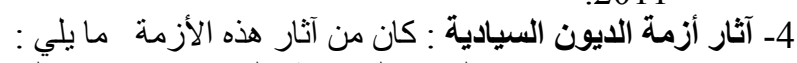

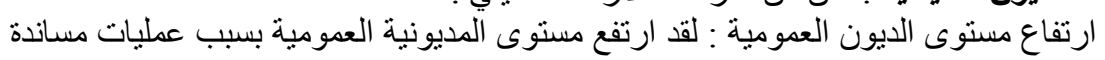

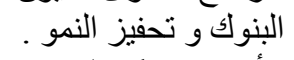

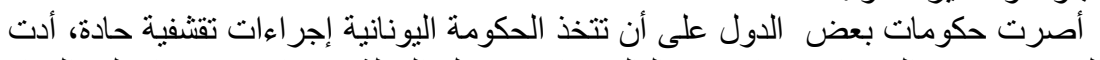

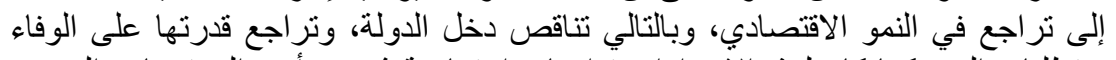

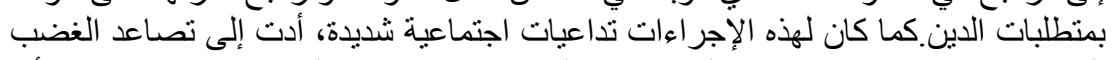

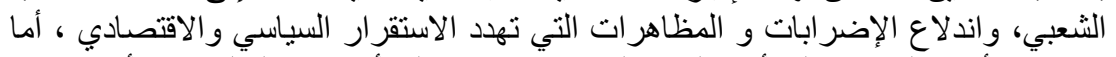

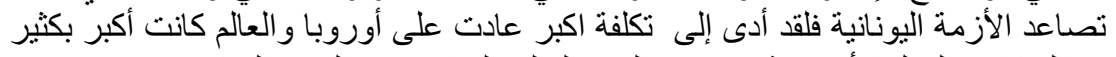

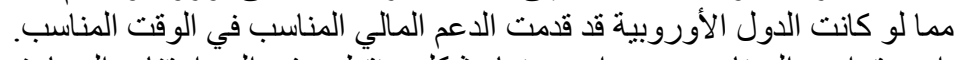

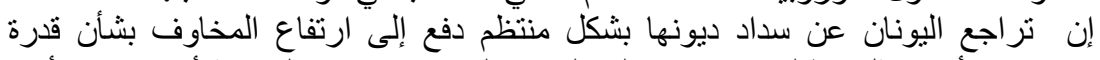

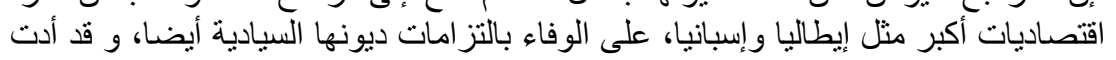


هذه المخاوف إلى إعادة تصنيف الموقف الايتماني لإيطاليا، مما رفع من سعر الفائدة الذي تسنطيع الاقتر اض به من القطاع الخاص. الفاص.

انخفاض النشاط الاقتصادي في منطقة اليورو خاصة مقارنة بباقي العالم كما يوضحه الجدول

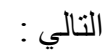

جدول رقم (3) تطور : ات الناتج الداخلي الخام بالأسعار الثابتة (نسبة التغير ) ما بين 2010 و 2015 في

\begin{tabular}{|c|c|c|c|c|c|c|}
\hline \multicolumn{7}{|c|}{ عدد من المناطق و العالم } \\
\hline 2015 & 2014 & 2013 & 2012 & 2011 & 2010 & المنطقة/السنوات \\
\hline 3.451 & 3.389 & 3.408 & 3.404 & 4.169 & 5.379 & العالم \\
\hline 1.453 & 0.881 & $0.455-$ & -0.811 & 1.616 & 2.025 & منطقة اليورو \\
\hline 1.847 & 1.397 & 0.115 & $0.411-$ & 1.799 & 2.049 & الاتحاد الأوروبي \\
\hline
\end{tabular}

Source: International Monetary Fund, World Economic Outlook Database, April 2015 retrieved le 24-02-2016

يظهر لنا من الجدول السابق انخفاض النشاط الاقتصادي في الاتحاد الأوروبي ككل مقارنة بالعالم الذي

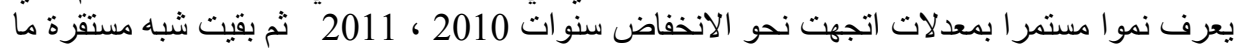

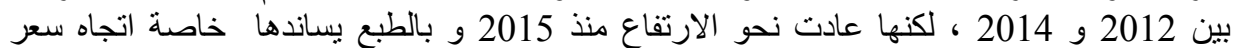

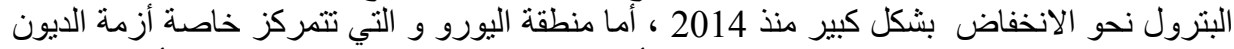

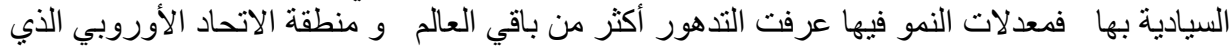

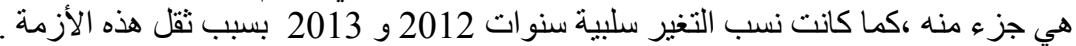

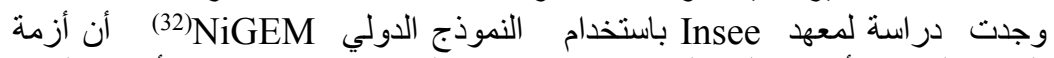

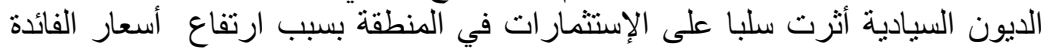

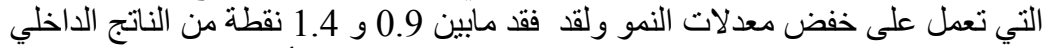

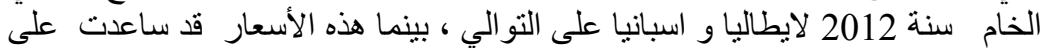

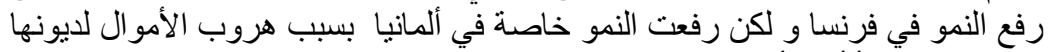

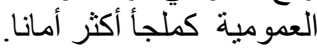

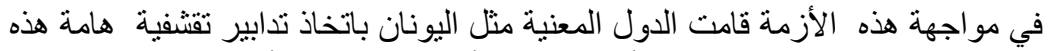

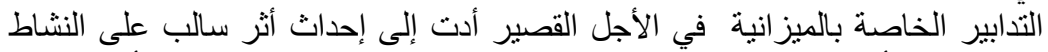

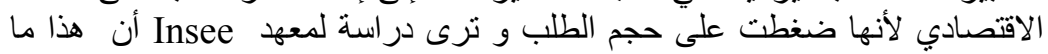

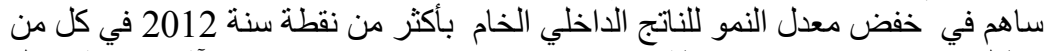

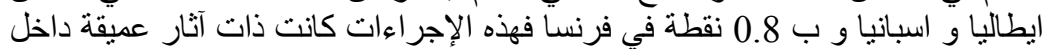

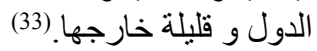

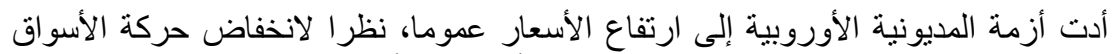

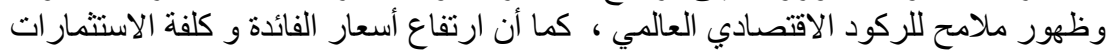

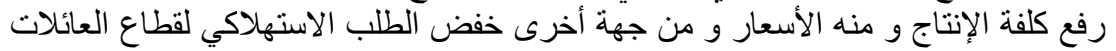

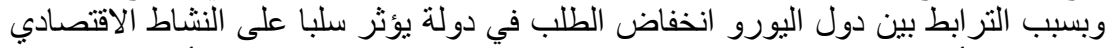

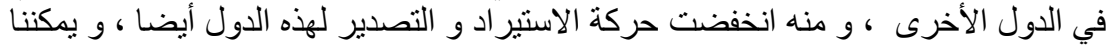

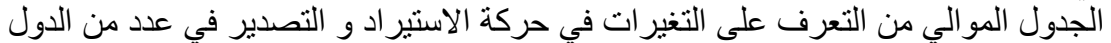

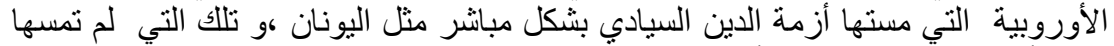
هذه الأزمة بشكل مبانشر مثل ألمانيا : الأبنا

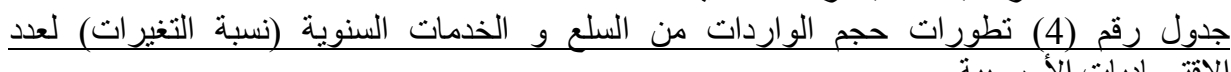
الاقتصاديات الأوروبية نطية 


\begin{tabular}{|c|c|c|c|c|c|c|}
\hline 2015 & 2014 & 2013 & 2012 & 2011 & 2010 & الاول/السنة \\
\hline 0.15 & 8.06 & $13.60-$ & $4.59-$ & $0.61-$ & 4.52 & قبرص \\
\hline 4.52 & 3.76 & 1.89 & $1.29-$ & 6.28 & 8.86 & فرنسا \\
\hline 4.49 & 3.35 & 3.13 & $0.01-$ & 7.14 & 12.85 & ألماتيا \\
\hline 8.61 & 8.84 & $4.65-$ & 14.42- & 9.04- & $5.48-$ & اليونان \\
\hline 4.4 & 13.17 & 0.64 & 6.91 & $0.6-$ & 3.01 & ايرلندا \\
\hline 2.14 & 1.79 & $2.32-$ & $8.13-$ & 0.52 & 12.39 & ايطاليا \\
\hline 3.93 & 6.6 & 6.7 & $11.35-$ & $5.46-$ & 2.91- & البرتغال \\
\hline 8.67 & 7.62 & $0.47-$ & 6.31- & $0.79-$ & 6.92 & اسبانيا \\
\hline
\end{tabular}

Source : International Monetary Fund, World Economic Outlook Database, April 2015 retrieved le 24-02-2016

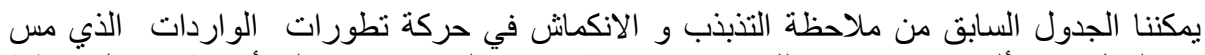

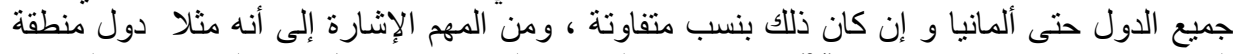

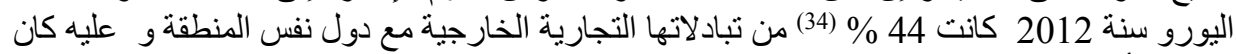
ضرر الأزمة واضحا فيها. جدول رقح (5) نطور ات حجم الصسادرات من السلع و الخدمات السنوية (نسبة التغير ات) لعدد من دول

\begin{tabular}{|c|c|c|c|c|c|c|}
\hline 2015 & 2014 & 2013 & 2012 & 2011 & 2010 & الدول/السنة \\
\hline $0.05-$ & 5.72 & $4.98-$ & $1.66-$ & 4.21 & 2.63 & قبرص \\
\hline 5.5 & 2.66 & 2.36 & 1.07 & 6.87 & 9.01 & فرنسا \\
\hline 4.32 & 3.85 & 1.57 & 2.82 & 8.00 & 14.53 & ألمانيا \\
\hline $0.31-$ & 8.84 & 2.82 & $0.25-$ & 0 & 4.63 & اليونان \\
\hline 5 & 12.61 & 1.12 & 4.69 & 5.48 & 6.17 & ايرلندا \\
\hline 4.18 & 2.66 & 0.5 & 2.34 & 5.18 & 11.78 & ايطاليا \\
\hline 5.87 & 4.04 & 11.91 & $2.72-$ & 8.97 & 0.48 & البرتغال \\
\hline 6.32 & 4.15 & 4.29 & 1.17 & 7.39 & 9.43 & اسبانيا \\
\hline
\end{tabular}

Source: International Monetary Fund, World Economic Outlook Database, April 2015 retrieved le 24-02-2016

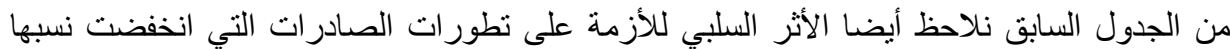

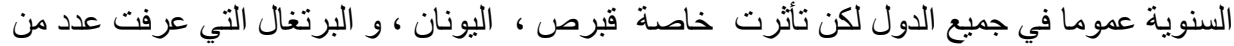

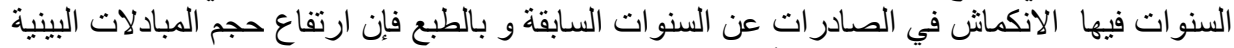
بين دول منطقة اليورو ساهم في هذا الأثر السلبي.

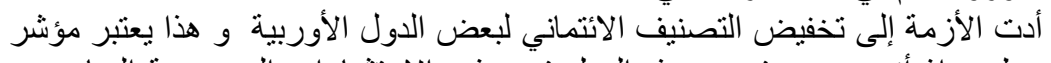

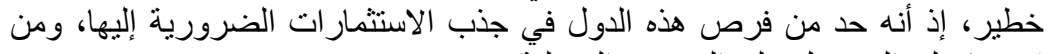

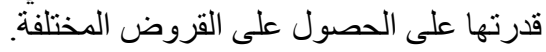

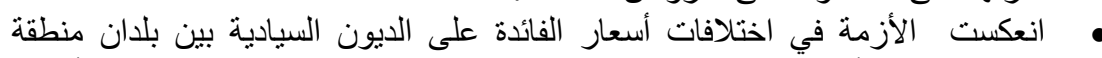
اليورو و كانت أنقل على بلدان الجهة الجنوبية من المنطقة ولكن عموما ارتفعت الأسعار 
المدفوعة من منطقة اليورو مقارنة بمثيلاتها في الولايات المتحدة الأمريكية أو بريطانيا

شكل رقم (3) تطورات أسعار الفائدة على السندات الحكومية ما بين 2008 و 2012 في بعض دول اليورو دول منطقة

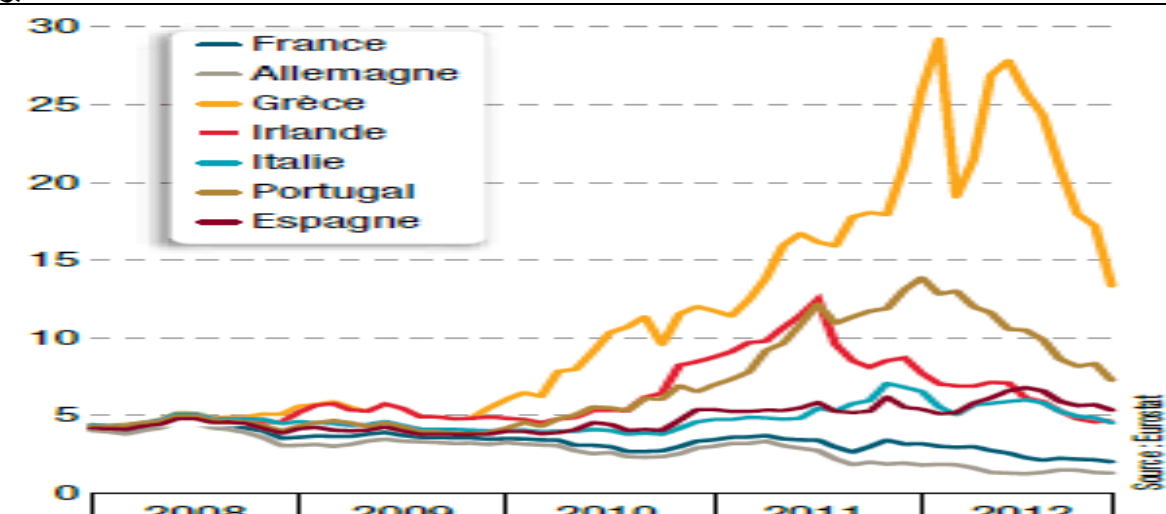

Source :eurostat , retrieved from http://ec.europa.eu/eurostat يمكننا الثكل السابق من معرفة أن أسعار الفائدة على الدين السيادي قد ارتفعت لدى عدد من الدول والئ وهي

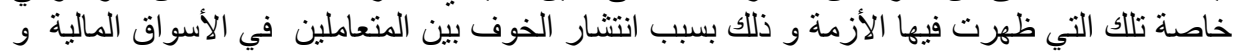

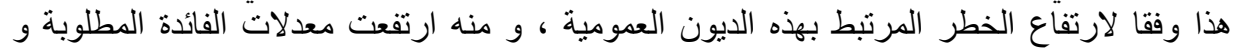

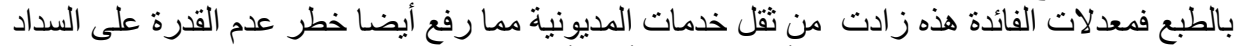

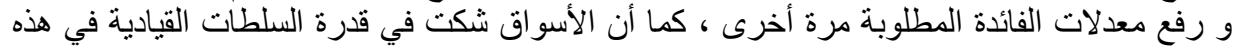

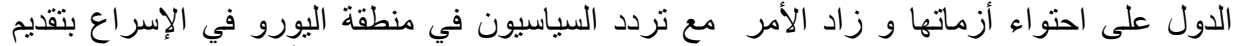

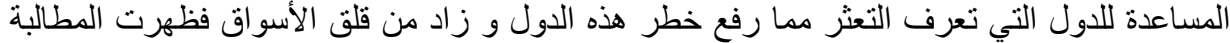

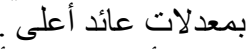
ولقد أثرت هذه الأسعار المرتفعة سلبا على النمو فيها فحسب دراسة لمعهد

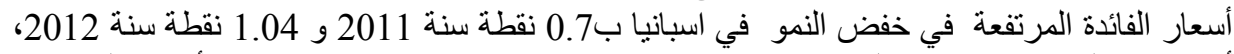

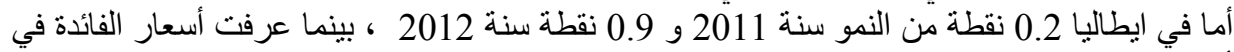

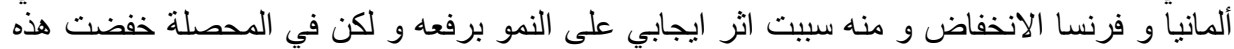

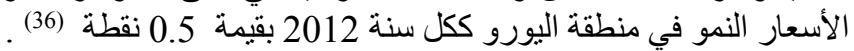

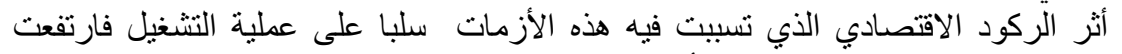

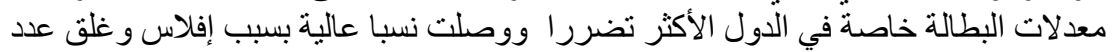

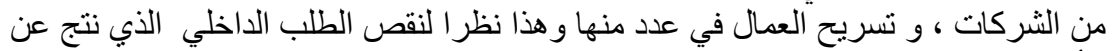

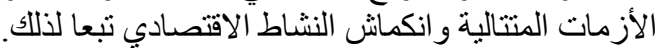

جدول رقم (6) تطور ات معدلات البطالة كنسبة من القوة العاملة في عدد من دول أوروبات

\begin{tabular}{|c|c|c|c|c|c|c|}
\hline 2015 & 2014 & 2013 & 2012 & 2011 & 2010 & الدول/السنة \\
\hline 15.9 & 16.17 & 15.91 & 11.88 & 7.9 & 6.29 & قبرص \\
\hline 10.08 & 10.2 & 10.26 & 9.8 & 9.2 & 9.28 & فرنسا \\
\hline 4.85 & 4.98 & 5.21 & 5.36 & 5.8 & 6.93 & ألماتيا \\
\hline 24.79 & 26.94 & 27.46 & 24.43 & 17.86 & 12.71 & اليونان \\
\hline 9.82 & 11.26 & 13.04 & 14.67 & 14.62 & 13.85 & ايرلندا \\
\hline 12.60 & 12.80 & 12.15 & 10.62 & 8.4 & 8.38 & ايطاليا \\
\hline
\end{tabular}




\begin{tabular}{|r|r|r|r|r|r|r|}
\hline 13.06 & 13.89 & 16.18 & 15.52 & 12.67 & 10.77 & البرتغاليال \\
\hline 22.56 & 24.45 & 26.1 & 24.8 & 21.4 & 19.85 & البانيا \\
\hline
\end{tabular}

Source: International Monetary Fund, World Economic Outlook Database, April 2015 retrieved le 24-02-2016

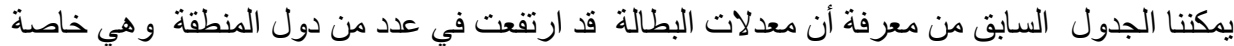

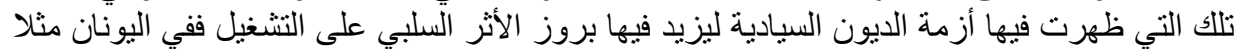

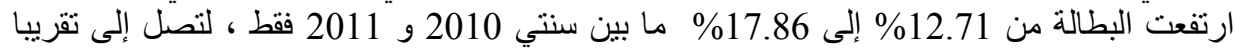

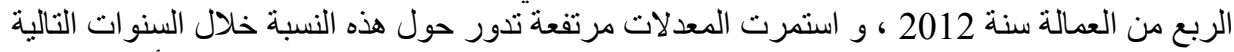

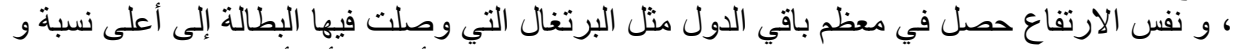

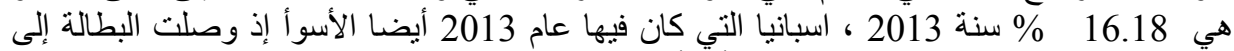

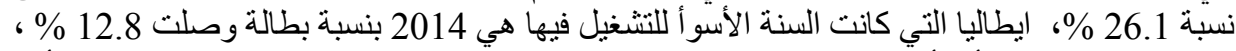

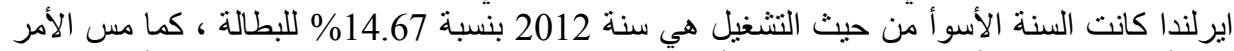
دول أخرى بمعدلات أقل مثل فرنسا ، غير أنه يمكننا ملاحظة انخفاض مستويات البطالة في ألمانيا خلال الال

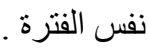

إن اليونان وفي حالة عدم التمكن من الوفاء بالتز امات الدين كانت ستضطر لإعلان إفلاسها،

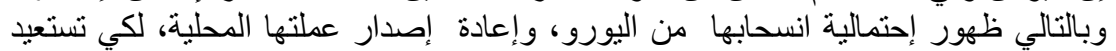

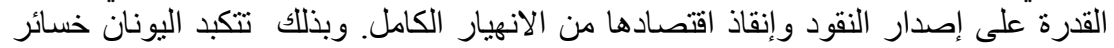

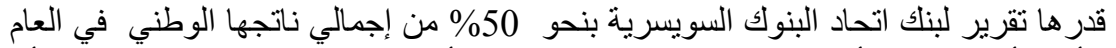

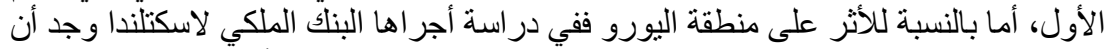

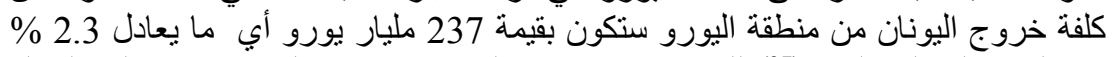

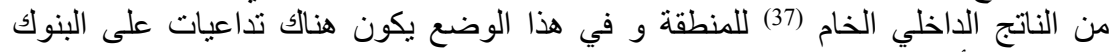

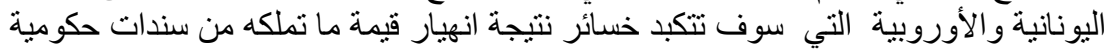

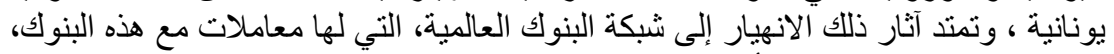

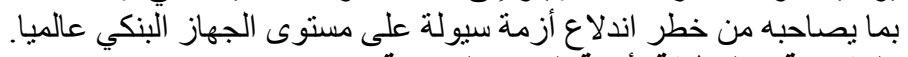

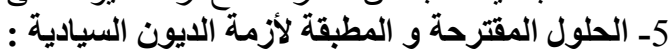

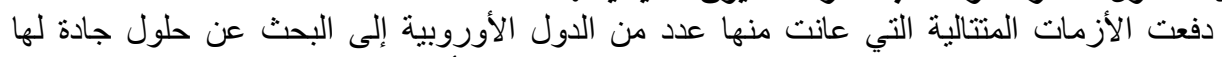

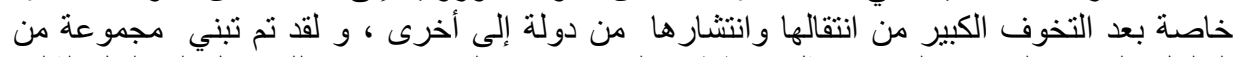

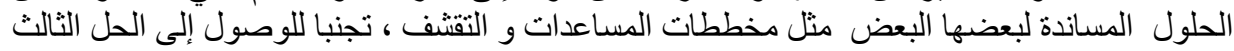

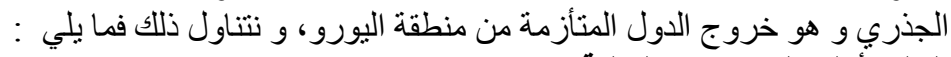

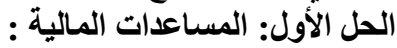

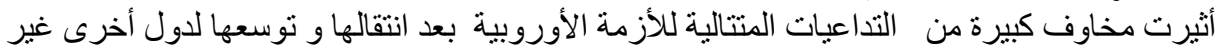

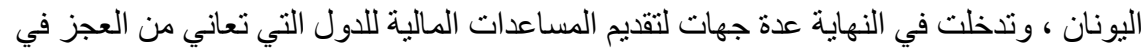

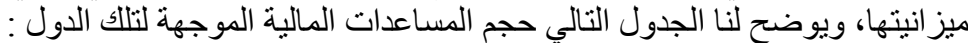
جدول رقم (7) المساعدات المالية المقدمة للاول الأوروبية المنأثرة بأزمة الديون السيادية الدية ، الوحدة مليار 


\begin{tabular}{|c|c|c|c|c|}
\hline الإجمالي & صندوق النقد الدولي & اليورو منطقة & تاريخ المو افقة & البلد \\
\hline $\begin{array}{rr} & 110 \\
& \\
& \\
& \\
& \\
& \\
& \end{array}$ & 30 & 80 & اكتوبر 2010 مايل 2011 م 2015 & اليونان \\
\hline 67.5 مليار & & & ديسمبر 2010 & ايرلندا \\
\hline 78 مليار & 26 & 52 & ماي 2010 & البرتغال \\
\hline 10 مليار استخدمت منها 7 & & 10 & مارس 2013 & قبرص \\
\hline
\end{tabular}

المصدر : معطيات من منشورات صندوق النقد الدولي الموفي

Wwww.lemonde.fr

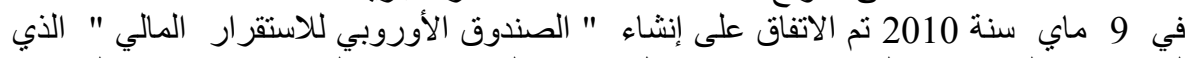

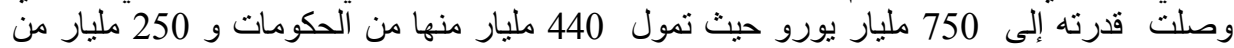

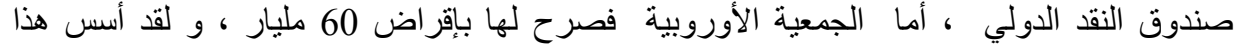

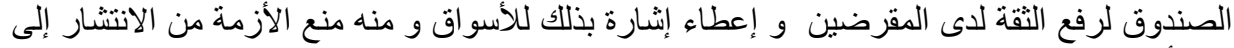

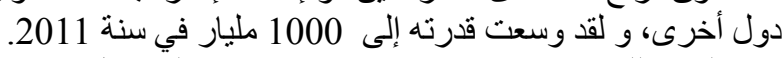

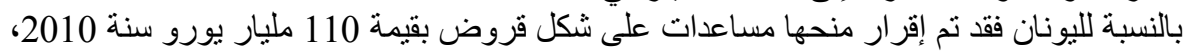

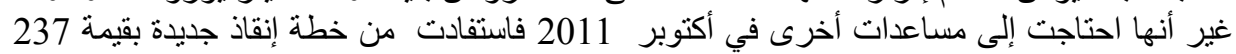

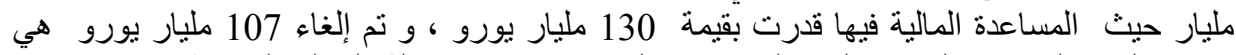

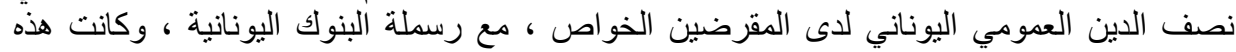

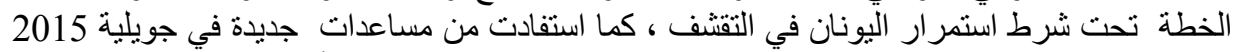

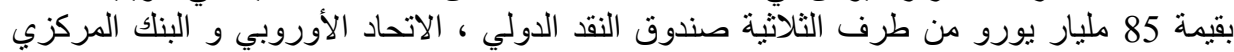

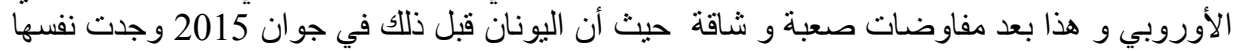

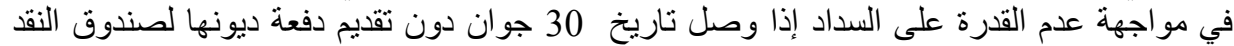

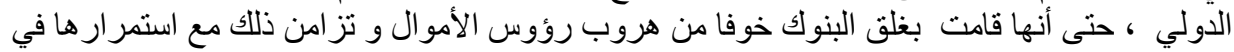
رفض الثروط المرتبطة بالمساعدات المالية المقدمة ، لذلك برزت الثرت خلال هذه الفترة بثدة فكرة خروجها

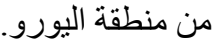

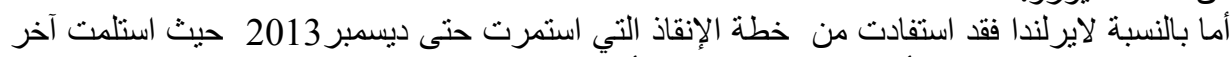

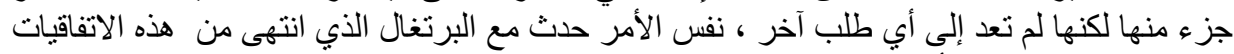

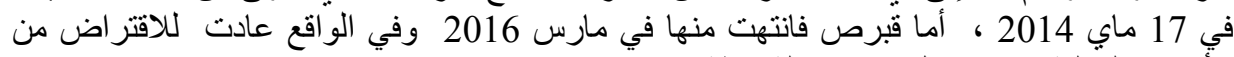

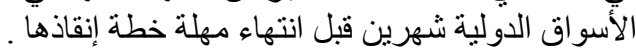

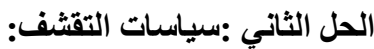
لحل الأزمة أجبرت الدول على تطبيق سياسات تقفتف للحد من عجز الميز انيات في الدول و التمكن من

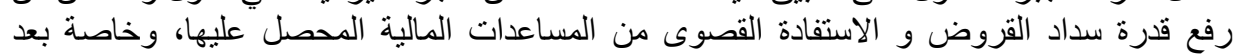

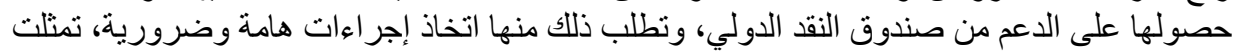




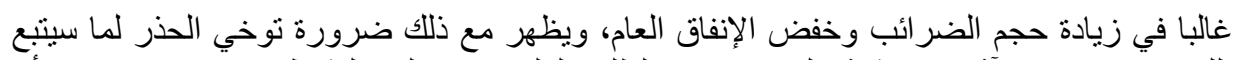

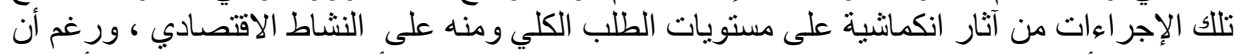

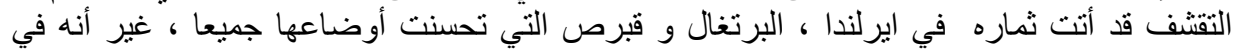

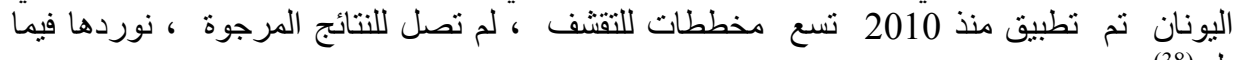

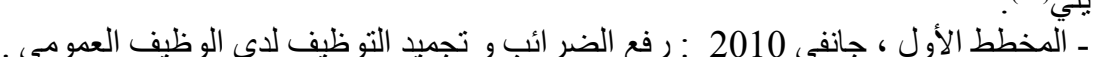

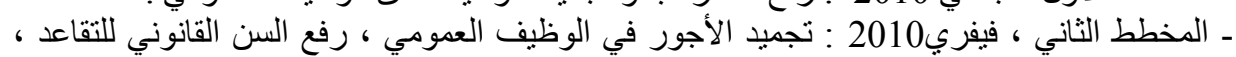

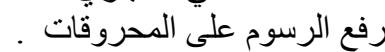
ـ المخطط الثالث ، مارس 2010 :تجميد معاثات التقاعد، رفع الرسوم على عدد من السلع مثل التبغ و

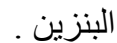
ـ البخطط الر ابع، ماي 2010 : إلغاء الثهر الثالث عشر و الر ابع عشر من حسابات التقاعد و الوظيف

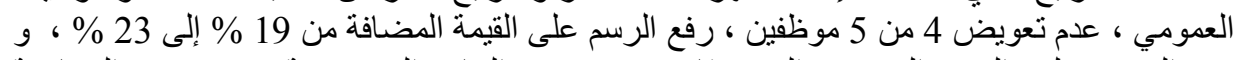

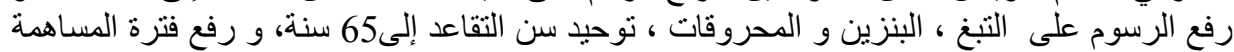
في الضمان الاجتماعي إلى الى 40 سنة.

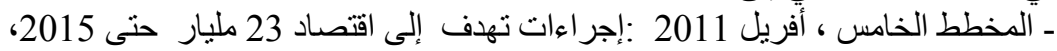

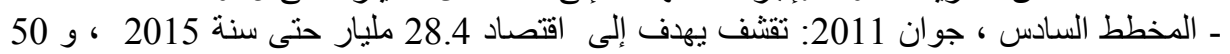

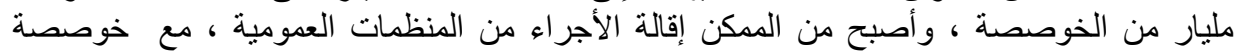

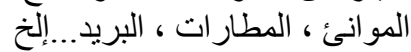
ـ المخطط السابع ، سبتمبر 2011 :نت إنثاء رسم خاص على الملكية العقارية ، و نم تثديد بعض

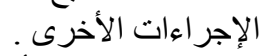
ـ المخطط الثامن ، أكتوبر 2011 : خفض مرنبات التقاعد ، تسريح 30000 عون عمومي و إجراءات ـ أخرى. المخط التاسع، جويلية 2015 :إدخال تعديلات على الرسم على القيمة المضافة ، إضافة إصلاحات

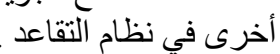

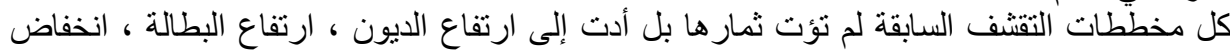

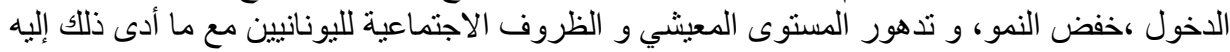

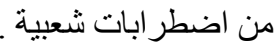

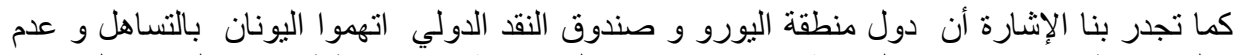

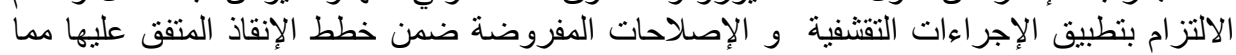

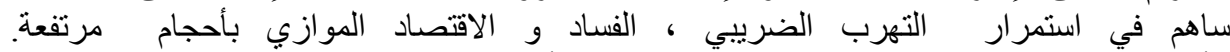

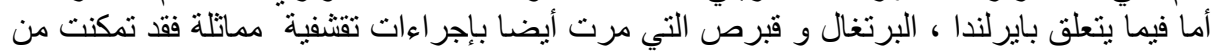

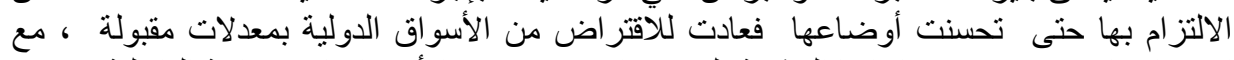

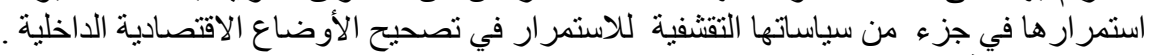

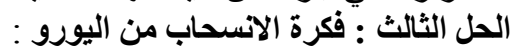

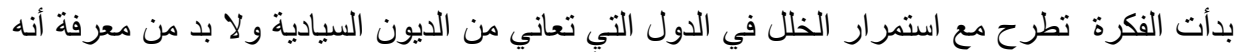

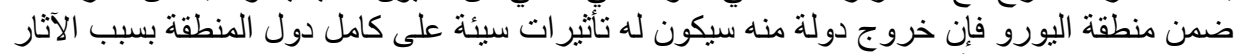

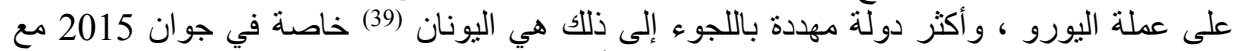

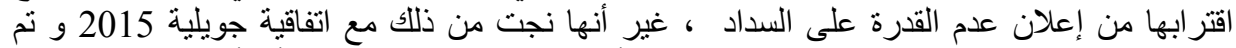

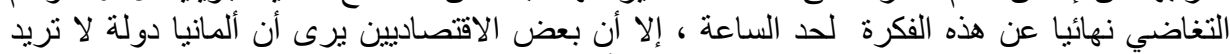

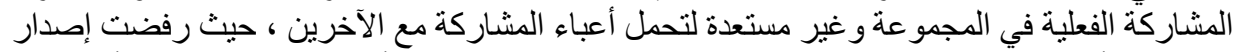

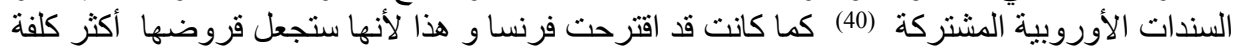
و تتحمل أعباء إضافية ليست السبب فيها ، كما رفضت تغيير مهام البنك المركزي الأوروبي لتنماتل 


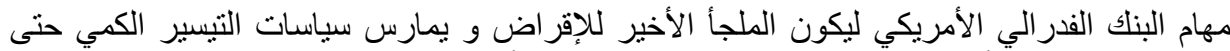

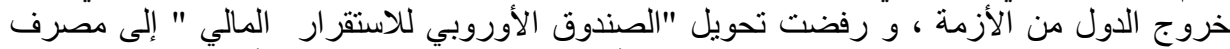

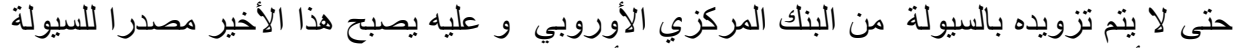

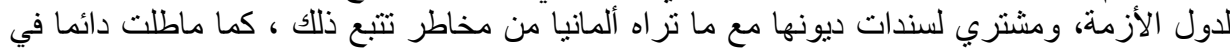

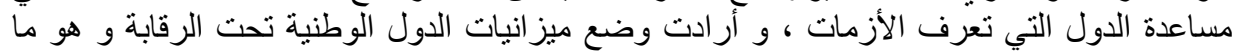

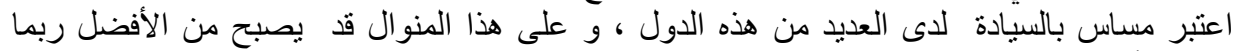

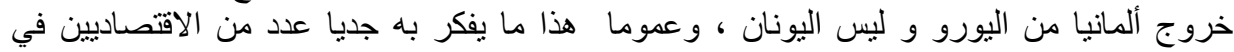
المنطقة.

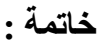

حاولنا من خلال هذا البحث أن نجيب على تساؤلنا الرئيسي ما هي أهم الأزمات التي مست الناحية الأنية

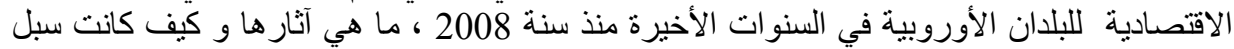

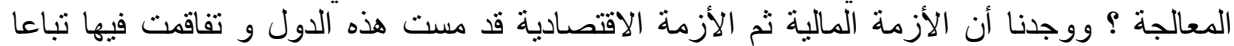

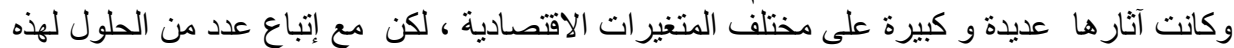

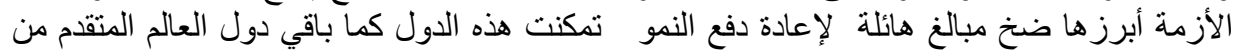

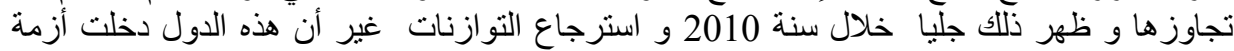

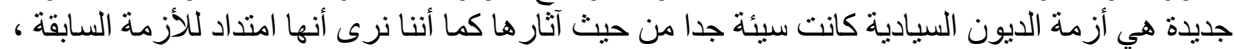

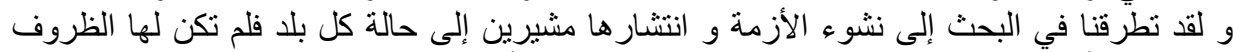

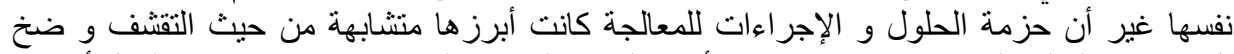

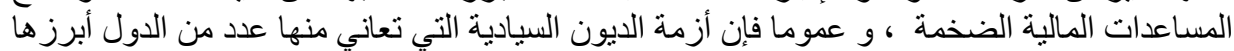

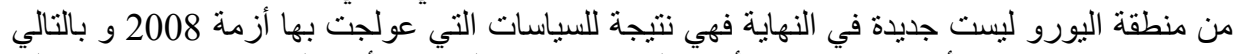

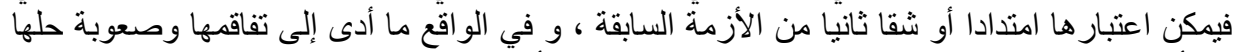

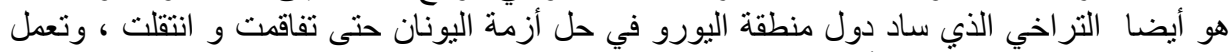

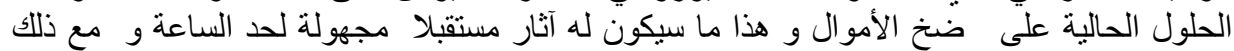

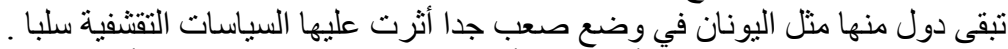

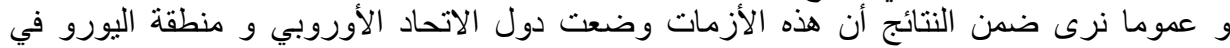

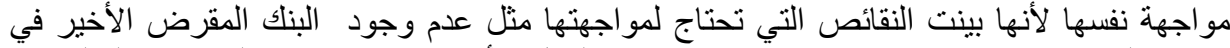

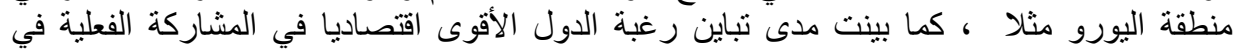

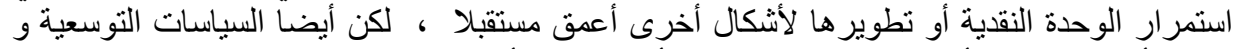

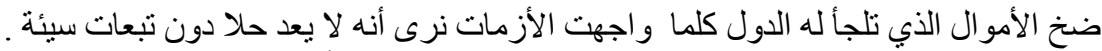

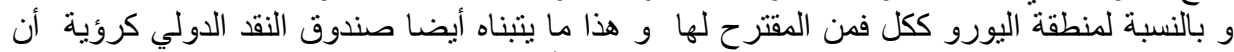

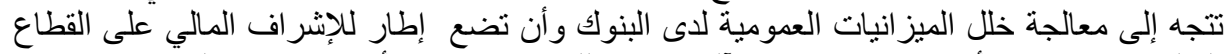

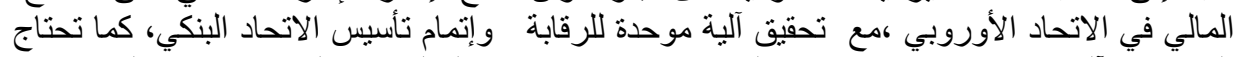

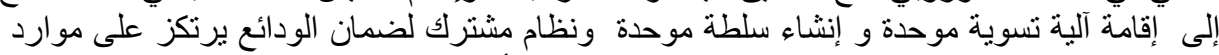

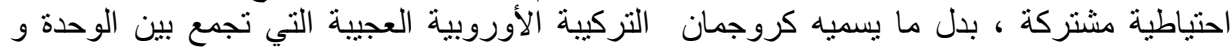

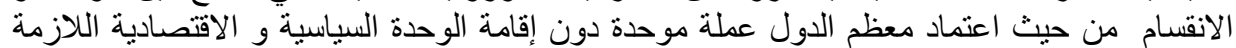

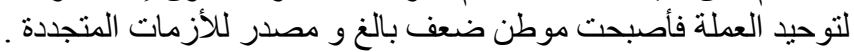

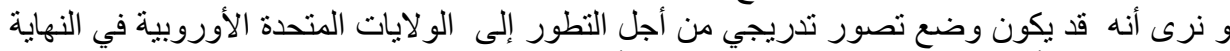

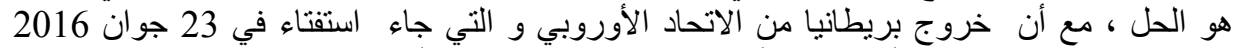
مساندا لها قد تغير خارطة الأحداث و الأزمات مجددا لدى الاتحاد الأوروبي . 
1 المراجع كروجمان الإحالات : أنهوا هذا الكساد الآن ،ترجمة أميرة إمبابي ، الطبعة الأولى 2015 ، مؤسسة

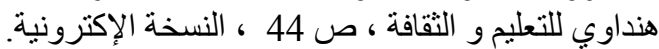

1 La Banque des règlements internationaux Sur le lien http://www.bis.org

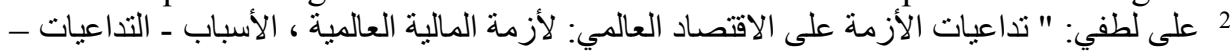

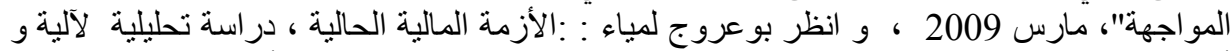

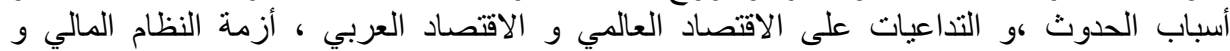

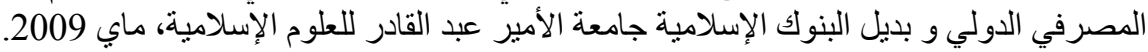

${ }^{3}$ Kenneth Rogoff économiste du FMI et Pr à Harvard in "Trends Tendances" du 18/09/2008 P: 18.

4 Bernard Zimmen " Chiffres clés de la crise financière in Nikkei journal économique japonais du 6 au 14 octobre 2008.

${ }^{5}$ Pour plus d'informations voir :

5 قناة الجزيرة : بريطانيا تضخ 250 مليار جنيه لإنقاذ بنوكها ، مسترجعة من http://www.aljazeera.net/news/ebusiness

PLANE, Mathieu et PUJALS, Georges. Les banques dans la crise. Revue de l'OFCE, 2009, no 3, p. 179-219.

${ }^{7}$ AMAR, Michel, DALIBARD, E., et DEBAUCHE, E. La crise de 2008-2009 et ses suites: recul marqué de l'emploi et ralentissement des salaires, puis reprise en 2010. Emploi et salaires, 2011, p. 9-17.

${ }^{8}$ BRICONGNE, Jean-Charles, FOURNIER, Jean-Marc, LAPÈGUE, Vincent, et al. De la crise financière à la crise économique. L'impact des perturbations financières de 2007 et 2008 sur la croissance de sept pays industrialisés.

Économie et statistique, 2010, vol. 438, no 1, p. 47-77

${ }^{9}$ CABANNES, Pierre-Yves, COTTET, Vincent, DUBOIS, Yves, et al. Les ajustements des entreprises françaises pendant la crise de 2008/2009. Dossier, INSEE, available at $w w w$. insee.

fr/fr/ffc/docs_ffc/ref/ECOFRA13c_D1_entrepr. pdf, 2013.

10 la commission europeenne sur le lien : https://ec.europa.eu/commission/index_fr

11 La Banque centrale européenne sur le lien http://www.ecb.europa.eu/ecb/history/emu/html/index.fr.html 12 ibidem

${ }^{13}$ Ministère de l'économie , trésor, sur le lien https://www.tresor.economie.gouv.fr/

${ }^{14}$ La Banque centrale européenne sur le lien http://www.ecb.europa.eu/ecb/history/emu/html/index.fr.html

15 إسلى 15

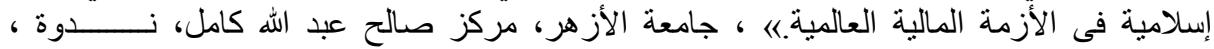


》الأزمة المالية العالمية من منظور إسلامي وتأثثر ها على الاقتصادات العربية/ ، يوم السبت 11 من

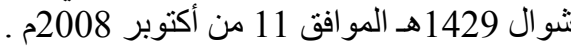

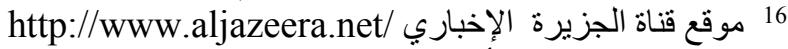

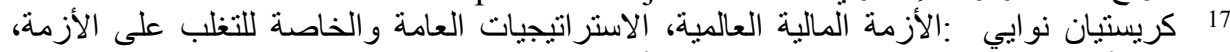
باريس - أوروبلاس، زيارة إلى البحرين وقطر وأبوظبي ودبي ، يناير الإنئ (كانون الثاني) 2009 18 18

19 موقع قناة الجزيرة الإخباري: بريطانيا تستعد لأكبر خطة إنقاذ مالي في تاريخها ، الأحد

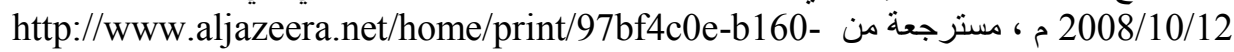
الاطع 4e00-8a8b-af44be2d88ae/ff5749d1-10e1-4e3d-8d4f-902e3704e61c الاطلاع في 23- 2016-02

${ }^{20}$ L'Institut national de la statistique et des études économiques sur le lien https://www.insee.fr

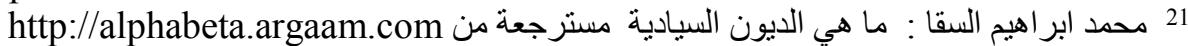
${ }^{22}$ Le Fonds Monétaire International sur le lien http://www.imf.org

23 Nelson, et.al. Greece's debt crisis: overview, Policy, Reponses, and Implication, Congressional Research Service, August, 2011, p.9.

${ }^{24} \mathrm{~S} \& \mathrm{P}$ global market intelligence : global sovereign risk report retrieved from http://www.cmavision.com/images/uploads/docs/CMA_Global_Sovereign_Cre dit_Risk_Report_Q3_2012.pdf

${ }^{25}$ S\&P Capital IQ McGraw Hill Financial : Global Sovereign Debt Report - A Market Driven perspective4tquarter2014.retrievedfrom images.info.standardandpoors.com/Web/StandardandPoors/\{7e120ebe-a96d4929-94ac-

afad09d4ed3a\}_Sov_Report_Q4_2014_(Final).pdf?utm_medium=Email\&utm source=Eloqua 20-02-2016

${ }^{26}$ Ibid

${ }^{27}$ Dadush, U., Paradigm Lost “ The Euro in Crisis”, Carnegie Endowment for International Peace, Washington,2010, pp, 45-47.

28 الغرفة التجارية الصناعية بالرياض : التقرير الاقتصادي ، الاقتصاد العالمي رهن الإن الديون الامريكية

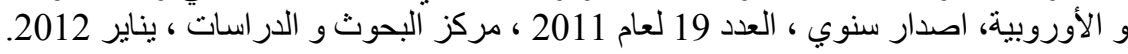
${ }^{29}$ Stefan Hofrichter :Crise de la dette de la zone euro . L'Union Economique et Monétaire (UEM) - Vers un effondrement ou une intégration renforcée de la zone euro ?. d'Allianz Global Investors.

30 Banque nationale de Belgique : rapport 2012, la crise dans la zone euro retrieved from https://www.nbb.be/doc/ts/publications/nbbreport/2012/fr/t1/rapport2012_tii_h 1.pdf le 26-02-2016

31 André cartapanis : après la crise de la dette souveraine ; la zone euro au bord de la récession, Conférnce - débat de la représentation régionale de la commission européenne , Marseille 3/ 04/2012 
${ }^{32}$ Matthieu Lequien, . Dorian Roucher : . Prix du pétrole et crise de la dette : quels effets sur la croissance en zone euro ? Insee Analyses . $\mathrm{n}^{\circ} 7$ - décembre 2012

${ }^{33}$ Ibid

${ }^{34}$ Clément Bouillet : Commerce intra-Zone Euro: et maintenant, on va où? BSI Economics , retrieved from http://www.bsieconomics.org/images/articles/a159.pdf

${ }_{35}$ Matthieu Lequien, . Dorian Roucher : opcit

${ }^{36}$ Ibid

${ }^{37}$ Les echos ; le «GRexit» en dix questions, du 07/09/2015 retrieved from http://www.lesechos.fr/09/07/2015/lesechos.fr/021198411174_le---grexit---endix-questions.htm\# le 10/10/2015

38 * jean luc elenchon : L'échec de la rigueur : les 8 plans d'austérité grecs : http://www.jean-luc-elenchon.fr/arguments/lechec-de-la-rigueur-les-8-plansdausterite-grecs/

* Le Monde : La crise grecque en neuf plans d'austérité, trois plans d'aide et une réélection, sur le site www.lemonde.fr

${ }^{39}$ Pascale micoleau-marcel :L'euro, l'europe et votre argent, la crise de l'euro , conférence débat 3/04/2012 .

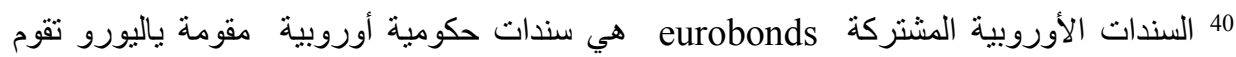

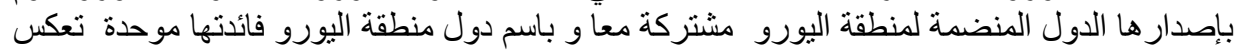

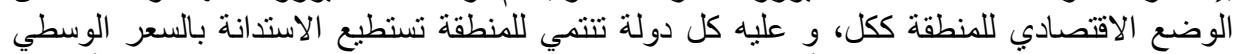

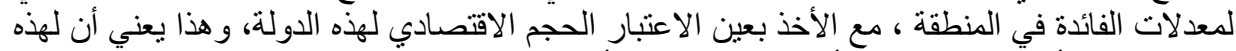
القروض كلفة أعلى على الدول الأقوى اقتصاديا مثل ألمانيا. 